\title{
ANÁLISIS ARQUEOBOTÁNICO DE PIEZAS DE MADERA DEL EXTREMO AUSTRAL AMERICANO
}

\author{
LAURA CARUSO FERMÉ*, MYRIAN ÁLVAREZ"* Y MARTÍN VÁZQUEZ"**
}

\begin{abstract}
RESUMEN
La preservación de arcos y astiles en el registro arqueológico patagónico es sumamente escasa. No obstante, para el caso concreto de Tierra del Fuego la información etnográfica muestra un amplio uso de vegetales para la manufactura de este tipo de armas. A fin de superar el sesgo entre ambos registros, hemos llevado a cabo el análisis arqueobotánico y morfo-métricos de una colección de arcos y flechas del Museo del Fin del Mundo (Ushuaia, Argentina). El objetivo principal es generar información sobre las características del sistema de arco y flecha utilizados por los las sociedades cazadoras-recolectoras que habitaron la isla y determinar las etapas necesarias para la obtención y procesado del material leñoso. Los resultados obtenidos revelaron la explotación de materias primas hasta ahora desconocidas en la región.
\end{abstract}

PALABRAS CLAVE: arqueobotanica, arcos y astiles, cazadores-recolectores, Tierra del Fuego.

\section{ARCHAEOBOTANICAL ANAYSIS OF WOOD ARTIFACTS FROM SOUTHERN AMERICAN TIP}

\begin{abstract}
The preservation of bows and arrows in the archaeological record of Patagonia is rather scarce. However, in the specific case of Tierra del Fuego, the ethnographic information portrays a wide use of plants to manufacture these kinds of weapons. In order to overcome the biases between both records an archaeobotanical and morpho-metric study of a collection of bows and arrows from the Museo del Fin del Mundo (Ushuaia, Argentina) has been undertaken. The main objective is to obtain information about the performance characteristics of bows and arrows used by hunter-gatherer societies who inhabited this island and to determine the necessary stages of procurement and transformation of wood materials. The results have revealed the exploitation of raw materials which have not been acknowledged up to the present.

KEY WORDS: archaeobotany, bows and arrows, hunter-gatherers, Tierra del Fuego.

\footnotetext{
Laborator d'Arqueobotànica, Universitat Autònoma de Barcelona. Becària FPI. Grup GASA, unitat associada al CSIC. lcarusoferme@gmail.com.

* CADIC-CONICET. myrianalvarez@gmail.com.

* Museo del Fin del Mundo; CADIC-CONICET. vazquez_martin@speedy.com.ar.
} 


\section{INTRODUCCIÓN}

La aparición del sistema de arco y flecha ha sido un tema ampliamente discutido dentro de las ciencias antropológicas (entre otros, Knetch 1997; Hughes 1998; Ratto 2003). La posibilidad de alcanzar una presa a mayor distancia, la eficacia en el tiro, el conocimiento y habilidades técnicas requeridas para su manufactura y uso, debieron sin duda generar cambios en las estrategias organizativas de las sociedades del pasado.

Su análisis desde el registro arqueológico presenta, no obstante, una dificultad doble. En primer lugar, en la mayoría de los contextos arqueológicos sólo se conserva una parte menor del sistema: las puntas líticas u óseas. Sin embargo, la información etnográfica y experimental ha demostrado ampliamente la importancia de los mangos y astiles sobre la eficacia o las características de perfomance en los sistemas técnicos de caza. Por ejemplo, las propiedades físico-mecánicas de las maderas utilizadas como astiles influyen notoriamente en la estabilidad de la trayectoria de vuelo del proyectil (Ratto 2003). Asimismo, la masa del sistema técnico está dada por el largo, el diámetro y el peso específico de las maderas utilizadas como astiles (Ratto op.cit.). Estas observaciones ponen de manifiesto que la historia y la evolución del ser humano se encuentran profundamente ligada a la existencia del entorno vegetal cuya gestión no sólo representa la mera satisfacción del alimento. Ahora bien, los restos arqueobotánicos sólo se conservan en medios anaerobios o cuando se produce un proceso de carbonización que impide su descomposición (Hastorf 1999; Buxó et al. 2003). En consecuencia, la posibilidad de analizar astiles o arcos procedentes del registro arqueológico es poco frecuente.

La segunda dificultad en el estudio de la adopción del arco y flecha es determinar si las puntas líticas recuperadas en los yacimientos han sido utilizadas como armas empuñadas a mano o como proyectiles. La mayoría de estudios sobre esta temática se orientan hacia la delimitación de variables morfológicas y dimensionales basadas principalmente en estudios actualísticos sobre los requerimientos técnicos de los diferentes sistemas de captura.

Las colecciones etnográficas depositadas en los museos constituyen un recurso de conocimiento alternativo para acercarse no solo a la adopción del arco y flecha sino también a su fabricación. No obs- tante, cabe tener presente que su estudio comporta una serie de sesgos. Estas colecciones, muchas veces suelen estar formadas por objetos de procedencia poco específica reunidos bajo criterios disímiles: tienen una historia propia de formación (adquisición, clasificación, objetivos, etc.) como parte del patrimonio del museo. Pero además, en algunos casos, son el resultado de demandas concretas realizadas por la sociedad occidental motivadas por el exotismo de pueblos originarios fuertemente aculturados. Más allá de estos reparos, es indudable que los museos, como espacios de difusión, preservación e investigación científica abren la oportunidad de generar información relevante al estudio de la dinámica y organización de las sociedades pasadas.

El propósito general de este trabajo es generar información sobre las características del sistema de arco y flecha utilizados por los pueblos originarios del extremo sur sudamericano a partir del análisis de piezas etnográficas depositadas en el Museo del Fin del Mundo (Ushuaia, Tierra del Fuego, Argentina). Nos focalizaremos principalmente en el análisis del material leñoso.

Los objetivos específicos son: identificar la materia prima utilizada para la manufactura de arcos y astiles, determinar sus características morfométricas y las etapas necesarias para la obtención y procesado del material leñoso. Asimismo se incluyen datos derivados del análisis tecnomorfológico de las puntas de proyectil de estos astiles. La finalidad es brindar datos que aporten a la discusión, así como revalorizar las colecciones etnográficas depositadas en los museos bajo la perspectiva de una problemática científica.

El trabajo se estructura en dos partes. En la primera se revisan los antecedentes disponibles sobre el uso del arco y flecha en Tierra del Fuego teniendo en cuenta tres ejes: la información etnográfica, la información arqueológica y el estudio de colecciones de museo. En la segunda se presentan y discuten los datos obtenidos del análisis de los artefactos del Museo del Fin del Mundo.

\section{ANTECEDENTES}

\section{a) Información etnográfica}

Durante el siglo XIX e inicios del XX diversos etnógrafos y viajeros han aportado información 
detallada sobre las diversas actividades llevadas a cabo por los antiguos pobladores del extremo austral americano. Según los datos brindados en esas fuentes cuatros grupos etnográficos habitaban las islas y canales que conforman el archipiélago Magallánico-Fueguino: los Yámana, los Alakalufes, los Selk'nam y los Haush. Los dos primeros eran grupos cazadores-recolectores-pescadores, se movilizaban en canoas y su economía estaba orientada hacia la gestión de recursos marinos. Los Selk'nam y los Haush, en cambio, eran sociedades cazadorasrecolectoras terrestres con énfasis en la explotación del guanaco y con un uso complementario de los recursos litorales; esta ultima característica aún más marcada para el caso Haush.

Desde las primeras crónicas de los contactos entre occidentales y fueguinos se hace recurrente la existencia de arcos y flechas como parte destacada del repertorio de armas, sobre todo entre los cazadores pedestres. Las primeras menciones sobre su existencia, datan de 1580 y provienen del relato de la expedición de Sarmiento de Gamboa, donde se describe un violento encuentro en la zona de bahía Gente Grande, costa fueguina del Estrecho de Magallanes (Sarmiento de Gamboa 1768 [1988]).

Para el ámbito ocupado por los Yámana, las menciones unívocas sobre la existencia de arcos y flechas datan del siglo XVIII. Posteriormente, durante los siglos XIX y XX, las apreciaciones sobre el uso de arcos y flechas son de diversa índole; aunque en general coincidentes en que la gravitación de este tipo de armas fue considerablemente menor que entre sus vecinos (para una revisión ver Orquera y Piana 1999b).

De acuerdo a las fuentes históricas y etnográficas, el arco y la flecha era el arma principal de la sociedad Selk'nam que habitaba el norte y centro de la Isla Grande de Tierra del Fuego. Según diversos autores este grupo confeccionaba sus astiles con madera flexible obtenida de diversos arbustos, aunque el mayoritariamente se utilizaba Berberis ilicifolia Forst. -michay- (Bridges 1952, Chapman 1986, Cojazzi 1914, Gusinde 1982, Prieto 1994). Es así que astiles confeccionados con maderas más duras o de mayor peso específico como Pernettya mucronata Gaudich. ex G.Don -chaura- eran preferidos para la caza de mamíferos como guanacos, zorros o lobos (Chapman 1986: 58, Prieto 1994). Por el contrario, maderas más livianas como Ribes magellanica Poir -parrilla- eran preferidas para astiles utilizados en la cacería de aves marinas, ya que su flotabilidad las hacia más fácilmente recuperables (Chapman 1986:59). Otras especies utilizadas eran Berberis buxifolia Lam -calafate-, y Chiliotrichum diffusum (Forst.) Kuntze -mata negra-.

Gallardo (1910) brinda las medidas aproximadas de los astiles cuyo largo estaba comprendido entre los 76,2 y $63,9 \mathrm{~cm}$, con un diámetro en la parte central que rondaba entre los 10 y $7 \mathrm{~mm}$. Las puntas de flecha según Gusinde (1937) eran manufacturadas sobre una roca esquistosa o sobre vidrio de origen europeo; tenían entre 30 y $75 \mathrm{~mm}$ de largo total, el pedúnculo rondaba los 5 a $10 \mathrm{~mm}$.

En cuanto a la confección de arcos de madera, Gusinde (1937) señala la utilización de troncos de Nothofagus antarctica (G.Forst.) Oerst. -ñire- o Nothofagus betuloide (Mirb.) Oerst. -guindo-. La adecuación o preparación de la madera consistía en varios pasos. La madera era descortezada y desbastada hasta llegar finalmente al vástago. El trabajo continuaba con la extracción de virutas, mediante la utilización de un raspador de hierro. Para lograr la curvatura deseada del arco, al inicio y al cese de la actividad se coloca la madera sobre el fuego, a la vez que se doblaba y estiraba continuamente mientras se la trabaja. Finalmente se coloca el arco bajo tensión entre los troncos del armazón de la choza (Gusinde op. cit).

Las características generales del armazón del arco Selk'nam incluían un acanalado de extremo a extremo, sección transversal en forma de almendra y sus medidas aproximadas eran:

- Largo del armazón: 1,34 a 1,170 m.

- Espesor agarre del armazón: 3,3 a 4 cm.

- Distancia central del armazón a la cuerda: 12 a $25 \mathrm{~cm}$.

Los Yámana que habitaban la zona del canal Beagle, utilizaban el sistema de arco y flecha, según las fuentes, para la caza de guanacos, aves y nutrias. Por lo general para confeccionar sus astiles utilizaban madera de Maytenus magellánica Hook.f. -maitény Berberis ilicifolia -michay- (Gusinde 1937). Las puntas de flecha eran de tamaño pequeño; según Gusinde (1986:450) no superaban los $30 \mathrm{~mm}$, de los cuales $7 \mathrm{~mm}$ correspondían al pedúnculo que iba enastilado. Se manufacturaban con cuarzo, esquisto, obsidiana (Gusinde 1937:450), ágata y pedernal 
(Bridges 1897; Hyades y Deniker 1891: 360). En algunas citas aparecen además puntas de proyectil manufacturadas sobre hueso (Lothrop 1928: 156).

\section{b) Información arqueológica y modelos de asignación funcional}

Tal como se dijo al principio, las puntas constituyen la única evidencia que perdura de los sistemas técnicos de armas en la mayoría de contextos arqueológicos. Es por ello que se han generado diversos modelos tendientes a discriminar si se trata de proyectiles o armas no arrojadizas sobre la base a datos etnográficos y experimentales. Según Ratto (2003) los requerimientos técnicos de un proyectil que forma parte de un sistema de arco y flecha son:

- Bajo índice de refuerzo: el índice de refuerzo refleja los esfuerzos mecánicos que soporta el sistema técnico y puede evaluarse a través de la relación espesor/ ancho y de la tenacidad de la roca.

- Aerodinámica perfecta o normal medida a través de la simetría de la sección y transversal y de los bordes de la punta.

- Tipo de enmangue: el ancho de la base o del pedúnculo de una punta enmangada en un astil debería medir $<10 \mathrm{~mm}$.

- Penetración: que se define por la sección del ápice $<1 \mathrm{~mm}^{2}$ y por el ángulo en vista plana.

De acuerdo con estas expectativas, la aplicación del modelo a varios conjuntos procedentes de la costa norte del canal Beagle ha permitido identificar puntas líticas con esas características en los sitios Ajej I (1.400 AP), Túnel I (capa beta: $670 \pm 80)$, Shamakush I (1.020 \pm 100 A.P.) y VIII $(1.400 \pm 90$ AP) el Túnel VII $(100 \pm 45)$ y Lancha Packewaia (capas A y C: $455 \pm 85$ y posterior al 280 AP) (Orquera y Piana 1999a; Álvarez 2010). Su antigüedad y uso en la región fue corroborada además en el primero de los sitios por la identificación de una punta lítica clavada en una vértebra de lobo marino que por su tamaño y por la forma que impactó sobre la presa se infiere que fue arrojada mediante la utilización de un arco (Piana et al. 2007 y 2008).

Estas puntas fueron manufacturas con riolitas y cineritas metamorfizadas de la Formación Lemaire de origen local. Se trata de piezas pedunculadas de limbo triangular, de tamaño pequeño o mediano y de superficies variables. Presentan un diseño aerodinámico perfecto o normal (sensu Ratto 2003), pedúnculos menores a $10 \mathrm{~mm}$ y ángulos en vista plana menores a $45^{\circ}$.

Un aspecto interesante que surge a partir de la aplicación del análisis funcional de base microscópica se vincula con el uso de las maderas a lo largo de la secuencia de ocupación del canal Beagle. En los conjuntos líticos posteriores al 2.000 AP se produce un incremento sustancial de rastros vinculados con el trabajo de madera en coincidencia con el aumento significativo de las puntas de arma (por ejemplo Clemente 1995; Alvarez 2003, 2009). Para el procesamiento de maderas se utilizaron tanto instrumentos retocados como de filo natural y se ejercieron acciones de corte y raspado.

La información sobre las puntas de flecha en el centro y norte de la isla de Tierra del Fuego es más escasa. Los datos disponibles hasta la fecha indican la presencia de este tipo de armas en el sitio Puesto Pescador 1 recuperadas en el interior de la región toráxica de un esqueleto fechado en $335 \pm 35$ años AP 14C (Suby et al. 2008). Fueron manufacturadas sobre calcedonia roja y blanca; la primera mide $23,3 \mathrm{~mm}$ de largo por $11,10 \mathrm{~mm}$ de ancho, mientras que la segunda alcanza los 16,5 $\mathrm{mm}$ de largo y los $11,8 \mathrm{~mm}$ de ancho. En el sitio Ewan II localizado en el centro de la isla y datado a principios del siglo XX (Bogdanovic et al. 2009) fueron halladas puntas de flecha de vidrio de limbo triangular y aletas (De Angelis 2009).

\section{c) Estudios de colecciones de museo}

Las colecciones de objetos depositados en museos etnográficos y fotografías constituyen un singular documento no solo para ilustrar y dar forma a lo transcurrido durante los episodios de contacto, sino que brindan información en cuanto a la cultura material de un grupo y sobre todo posibilita el estudio de sociedades pasadas. A partir de las colecciones etnográficas se puede conocer tanto la diversidad de los artefactos utilizados como la tecnología empleada en su transformación (Piqué 2006). No obstante, cabe destacar que, como en toda colección etnográfica, queda reflejado el sesgo que dirigió la recolección de los objetos y la poste- 
Tabla 1. Dimensiones de los arcos (Piqué 2006).

\begin{tabular}{|c|c|c|c|c|c|c|}
\hline Museo & Inventario & $\begin{array}{c}\text { Longitud } \\
(\mathrm{mm})\end{array}$ & $\begin{array}{c}\text { Anchura } \\
(\mathrm{mm})\end{array}$ & $\begin{array}{c}\text { Grosor } \\
(\mathrm{mm})\end{array}$ & $\begin{array}{c}\text { Distancia cuerda- } \\
\text { vastago (mm) }\end{array}$ & Acabado superficie \\
\hline MPELP & 2886 & 1350 & 19 & 27 & 90 & Facetada longitudinalmente \\
\hline MPELP & 27487 & 1200 & 22 & 29 & 185 & Facetada longitudinalmente \\
\hline MPELP & 27486 & 86 & 16 & 21 & 40 & Facetas de talla, ligeramente pulida \\
\hline MPELP & SN1113 & 1375 & 23 & 31 & 100 & Facetada longitudinalmente \\
\hline MPELP & SN1112 & 1280 & 22 & 30 & 120 & Facetada longitudinalmente \\
\hline
\end{tabular}

rior sistematización museográfica. Por esta razón es posible encontrar colecciones etnográficas que incluyan toda clase de artefactos mientras que otras denotan un especial interés por alguno de ellos.

Muchos de los arcos y astiles recopilados en tierras americanas por etnógrafos y viajeros hoy se encuentran en museos europeos y americanos. Para el caso concreto de Tierra del Fuego existen distintos trabajos focalizados en el análisis de piezas depositadas en museos. Dentro del proyecto "Contrastación arqueológica de la imagen etnográfica de los canoeros magallánicos fueguinos en la costa norte del canal Beagle", dirigido por Vila y Piana, se analizaron colecciones etnográficas depositadas en diferentes museos europeos, con el objetivo de identificar aquellos materiales atribuibles a los cazadores-recolectores Yámana de la costa del Canal Beagle (Estévez et al. 2006). Las categorías de los materiales documentados son muy amplias; entre los ítems fueguinos más significativos destacan aquellos objetos relacionados con la obtención de alimentos, instrumentos para la obtención de otros bienes, utensilios y objetos socio-ideotécnicos. Dado que parte del material estudiado estaba catalogado con su procedencia étnica y que fue posible el registro de varios instrumentos atribuibles a los grupos cazadores-recolectores, se analizó la diversidad artefactual de Tierra del Fuego en relación con los grupos que se diferenciaron en época histórica (Estévez et al. 2006). Los materiales selk'nam son menos abundantes, se registraron un total de 64 artefactos hechos de madera o con fibras vegetales que corresponden a esta sociedad, entre ellos encontramos antorchas, arcos, collares, etc. A pesar de que este trabajo constituye un valioso aporte al estudio de las sociedades fueguinas, no nos permite obtener información sobre la morfología y etapas de producción de los instrumentos ya que sus objetivos eran otros.

Otro trabajo realizado con piezas depositadas museos es el estudio de Piqué (2006) llevado a cabo con las colecciones etnográficas del Museo Pigorini de Roma (Italia) -MPELP-. Este trabajo se centra en el estudio tecnológico de la madera de los artefactos fueguinos. Además del registro de diversos instrumentos elaborados con madera, el estudio se basa en el análisis de cinco arcos y nueve astiles (ver Tabla 1 y 2). Según la autora las dimensiones de los astiles estudiados es bastante regular, con una longitud entre 640 y $720 \mathrm{~mm}$, con un diámetro que oscila entre los seis y ocho $\mathrm{mm}$.

El trabajo de Ratto (2003) está orientado a estudiar la organización tecnológica de la caza y la relación entre variables morfo-dimensiónales de los astiles y las propiedades físico-mecánicas de las materias primas vegetales empleadas en

Tabla 2. Dimensiones de los astiles (Piqué 2006).

\begin{tabular}{|c|c|c|c|c|c|}
\hline Museo & Inventario & Longitud astil $(\mathrm{mm})$ & $\begin{array}{c}\text { Diámetro proximal } \\
(\mathrm{mm})\end{array}$ & $\begin{array}{c}\text { Diámetro medial } \\
(\mathrm{mm})\end{array}$ & $\begin{array}{c}\text { Diámetro distal } \\
(\mathrm{mm})\end{array}$ \\
\hline MPELP & 14546 & 695 & 4 & 7 & 3 \\
\hline MPELP & 27493 & 690 & 5 & 5 & 4 \\
\hline MPELP & 47858 & 640 & 5 & 6 & 5 \\
\hline MPELP & 56204 & 665 & 4 & 7 & 4 \\
\hline MPELP & 27509 & 680 & 5 & 7 & 4 \\
\hline MPELP & 14545 & 670 & 4 & 8 & 4 \\
\hline MPELP & 14555 & 700 & 5 & 5 & 4 \\
\hline MPELP & 1024 & 695 & 5 & 8 & 4 \\
\hline MPELP & 1025 & 720 & 5 & & 5 \\
\hline
\end{tabular}


su confección. Parte de su trabajo consistió en el registro morfológico de arcos y astiles etnográficos depositados en dos museos: Museo Etnográfico Ambrosetti (Buenos Aires) -ME- y el Museo de La Plata (La Plata, Buenos Aires) -MLP-. Entre el material estudiado destacan cuatro arcos atribuidos a la sociedad Selk'nam y cinco a la Yámana (tabla 3).

Por lo que respecta a los astiles, entre las piezas estudiadas, solo fue posible identificar su procedencia geográfica (ver tabla 4). Este trabajo no solo ofrece valiosa información de carácter morfológico de los artefactos, sino que permiten conocer la materia prima vegetal utilizada para su confección. Los astiles estudiados en ambos museos poseen poca variabilidad en su diseño independientemente de su longitud y peso (Ratto 2003).

Por último, uno de nosotros (Caruso 2008) efectuó un estudio de 4 astiles que conforman la colección del Museo de La Plata (La Plata, Buenos Aires) -MLP_1 (ver tabla 5). Este trabajo fue mo-

1 Estas cuatro piezas no han sido incluidas en el trabajo de N. Ratto (2003) tivado por la existencia de indicadores indirectos de utilización y trabajo en madera procedentes del sitio Ewan (ver más arriba) donde la recuperación de -raspadores, instrumentos retocados y puntas de proyectil en vidrio- permitió inferir la confección y uso de enmangues y útiles compuestos -arco y flecha. El objetivo de ese trabajo fue conocer los usos del material leñoso entre los cazadores recolectores Selk'nam y profundizar sobre las fases o etapas necesarias para la obtención de un determinado producto confeccionado mediante la utilización de esta materia prima.

Brevemente se puede destacar, a partir de ese estudio, que el proceso de fabricación de los astiles, ya descrito en el apartado de fuentes etnográficas, pudo ser corroborado. Según la orientación de las fibras se pudo determinar que los astiles estaban confeccionados a partir de un segmento de rama, lo que indica la segmentación previa del tronco. Posteriormente la superficie fue pulida sin registrarse, en ningún caso, las trazas de los instrumentos utilizados en el desbastado.

Tabla 3. Dimensiones de los arcos Selk'nam y Yamanas (Ratto 2003).

\begin{tabular}{|c|c|c|c|c|c|c|c|c|c|c|c|c|}
\hline \multirow{3}{*}{ Museo } & \multirow{3}{*}{ Inventario } & \multirow{3}{*}{ Etnia } & \multirow{3}{*}{$\begin{array}{l}\text { Longitud } \\
(\mathrm{mm})(1)\end{array}$} & \multicolumn{7}{|c|}{ Diametro } & \multirow{3}{*}{$\begin{array}{c}\text { Distancia de la } \\
\text { cuerda al blanck } \\
\text { (mm) }\end{array}$} & \multirow{3}{*}{ Taxón } \\
\hline & & & & \multicolumn{2}{|c|}{$\begin{array}{c}\text { Extremo } \\
\text { superior (mm) }\end{array}$} & \multicolumn{3}{|c|}{ Parte media $(\mathrm{mm})$} & \multicolumn{2}{|c|}{$\begin{array}{c}\text { Extremo } \\
\text { inferior (mm) }\end{array}$} & & \\
\hline & & & & AA & $\mathrm{BB}$ & AA & $\mathrm{BB}$ & $\mathrm{CC}$ & $\mathrm{AA}$ & $\mathrm{BB}$ & & \\
\hline ME & $905-4282-4$ & Selk'nam & 1335 & 14 & 15 & 29 & 28 & 23 & 13 & 12 & 85 & $\begin{array}{c}\text { Nothofagus } \\
\text { betuloides }\end{array}$ \\
\hline $\mathrm{ME}$ & 13265 & Selk'nam & 1730 & 17 & 15 & 40 & 28 & 20 & 20 & 16 & 105 & $\begin{array}{c}\text { Nothofagus } \\
\text { betuloides }\end{array}$ \\
\hline MLP & 2048 & Selk'nam & 1270 & 12 & 11 & 31 & 20 & 5 & 8 & 7 & 116 & $\begin{array}{c}\text { Nothofagus } \\
\text { betuloides }\end{array}$ \\
\hline MLP & 2109 & Selk'nam & 1220 & 13 & 12 & 28 & 24 & 6 & 14 & 12 & 140 & $\begin{array}{c}\text { Nothofagus } \\
\text { betuloides }\end{array}$ \\
\hline MLP & 2046 & Yámana & 1400 & 13 & 10 & 31 & 22 & 5 & 12 & 10 & 125 & $\begin{array}{c}\text { Nothofagus } \\
\text { betuloides }\end{array}$ \\
\hline MLP & 2047 & Yámana & 1265 & 15 & 11 & 31 & 23 & 2 & 12 & 9 & 210 & $\begin{array}{c}\text { Nothofagus } \\
\text { betuloides }\end{array}$ \\
\hline MLP & 2049 & Yámana & 1120 & 12 & 10 & 26 & 18 & 5 & 10 & 10 & 198 & $\begin{array}{c}\text { Nothofagus } \\
\text { betuloides }\end{array}$ \\
\hline MLP & $19540-76$ & Yámana & 1237 & 12 & 10 & 26 & 19 & 6 & 13 & 11 & 110 & $\begin{array}{c}\text { Nothofagus } \\
\text { betuloides }\end{array}$ \\
\hline MLP & 2047 & Yámana & 1525 & 11 & 10 & 27 & 22 & 6 & 12 & 11 & 65 & $\begin{array}{c}\text { Nothofagus } \\
\text { betuloides }\end{array}$ \\
\hline
\end{tabular}

(1) Largo del arco de extremo a extremo. 
Tabla 4. Dimensiones de los astiles (Ratto 2003).

\begin{tabular}{|c|c|c|c|c|c|c|}
\hline \multirow[b]{2}{*}{ Museo } & \multirow[b]{2}{*}{ Inventario } & \multirow[b]{2}{*}{$\begin{array}{l}\text { Longitud total de la } \\
\text { pieza }(\mathrm{mm})\end{array}$} & \multirow[b]{2}{*}{ Longitud de astil (mm) } & \multicolumn{3}{|c|}{ Diámetro } \\
\hline & & & & $\begin{array}{c}\text { Extremo superior } \\
(\mathrm{mm})\end{array}$ & Centro (mm) & $\begin{array}{c}\text { Extremo inferior } \\
(\mathrm{mm})\end{array}$ \\
\hline $\mathrm{ME}$ & $4291-52$ & 671 & 640 & 5 & 7 & 5 \\
\hline $\mathrm{ME}$ & $4291-83$ & 683 & 656 & 5 & 7 & 5 \\
\hline ME & $4291-66$ & 685 & 653 & 5 & 7 & 5 \\
\hline $\mathrm{ME}$ & $4291-59$ & 688 & 656 & 5 & 7 & 5 \\
\hline $\mathrm{ME}$ & $4291-48$ & 690 & 659 & 5 & 7 & 5 \\
\hline ME & 4291-47 & 692 & 652 & 5 & 7 & 5 \\
\hline $\mathrm{ME}$ & $4291-51$ & 685 & 653 & 5 & 7 & 5 \\
\hline $\mathrm{ME}$ & $4291-63$ & 695 & 668 & 5 & 6 & 5 \\
\hline ME & $4291-57$ & 705 & 670 & 5 & 7 & 5 \\
\hline ME & $4291-56$ & 708 & 668 & 5 & 7 & 5 \\
\hline ME & $4291-64$ & 711 & 678 & 5 & 7 & 5 \\
\hline ME & $4291-65$ & 718 & 685 & 5 & 7 & 5 \\
\hline $\mathrm{ME}$ & 4291-61 & 742 & 709 & 5 & 7 & 5 \\
\hline $\mathrm{ME}$ & $4291-62$ & 762 & 738 & 5 & 8 & 5 \\
\hline MLP & 2416 & 758 & 741 & 7 & 8,5 & 5 \\
\hline MLP & 2397 & 753 & 725 & 5 & 7 & 5 \\
\hline MLP & 2401 & 728 & 697 & 5 & 8 & 4 \\
\hline MLP & 2413 & 726 & 707 & 5 & 7 & 5 \\
\hline MLP & 2414 & 693 & 675 & 5 & 7 & 5 \\
\hline
\end{tabular}

Tabla 5. Dimensiones de los astiles (Caruso 2008).

\begin{tabular}{|c|c|c|c|c|c|c|c|c|c|c|c|c|c|}
\hline \multirow[b]{2}{*}{ Museo } & \multirow[b]{2}{*}{ 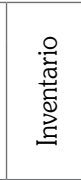 } & \multirow[b]{2}{*}{ Punta } & \multirow[b]{2}{*}{$\begin{array}{l}\text { Longitud } \\
\text { total de la } \\
\text { pieza (mm) }\end{array}$} & \multirow[b]{2}{*}{$\begin{array}{l}\text { Longitud } \\
\text { del astil } \\
\text { (mm) }\end{array}$} & \multicolumn{3}{|c|}{ Diámetro } & \multicolumn{3}{|c|}{ Características } & \multirow[b]{2}{*}{ 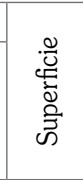 } & \multirow[b]{2}{*}{$\frac{\mathbb{N}}{\stackrel{\mathscr{N}}{0}}$} & \multirow[b]{2}{*}{ ص. } \\
\hline & & & & & $\begin{array}{c}\text { Extremo } \\
\text { superior } \\
\text { (mm) }\end{array}$ & $\begin{array}{c}\text { Centro } \\
\text { (mm) }\end{array}$ & $\begin{array}{c}\text { Extremo } \\
\text { inferior } \\
(\mathrm{mm})\end{array}$ & $\begin{array}{l}\text { Extremo } \\
\text { superior }\end{array}$ & $\begin{array}{l}\text { Extremo } \\
\text { inferior }\end{array}$ & $\begin{array}{c}\text { Ranura } \\
\text { para } \\
\text { flecha } \\
(\mathrm{mm})\end{array}$ & & & \\
\hline MLP & 4489 & $\begin{array}{c}\text { No } \\
\text { presenta }\end{array}$ & 720 & 720 & 5 & 8 & 5 & $\begin{array}{c}\text { Terminación } \\
\text { en punta }\end{array}$ & Engomado & $3 / 4$ & Pulida & $\begin{array}{c}\text { No } \\
\text { presenta }\end{array}$ & Rectilíneo \\
\hline MLP & 2399 & $\begin{array}{c}\text { No } \\
\text { presenta }\end{array}$ & 700 & 700 & 5 & 8 & 5 & Quebrado & $\begin{array}{c}\text { Engomado } \\
+ \\
\text { emplumado }\end{array}$ & 2 & Pulida & $\begin{array}{c}\text { No } \\
\text { presenta }\end{array}$ & Rectilíneo \\
\hline MLP & 4490 & $\begin{array}{c}\text { No } \\
\text { presenta }\end{array}$ & 750 & 750 & 6 & 8 & 6 & Quebrado & Engomado & $3 / 4$ & $3 / 4$ & $\begin{array}{c}\text { No } \\
\text { presenta }\end{array}$ & Rectilíneo \\
\hline MLP & 4492 & Quebrada & 740 & 755 & 7 & 8 & 6 & Punta & Engomado & 3 & Pulida & $\begin{array}{c}\text { No } \\
\text { presenta }\end{array}$ & Rectilíneo \\
\hline
\end{tabular}

\section{MATERIALES Y MÉTODOS}

Las colecciones etnográficas depositadas en el Museo del Fin del Mundo (Ushuaia, Tierra del Fuego, Argentina), constituyen un documento patrimonial que ilustra y materializa lo ocurrido en el momento de contacto entre los pueblos originarios fueguinos y las poblaciones europeas, posibilitando el estudio de estas sociedades cazadoras-recolectoras a partir de su cultura material.
Las colecciones etnográficas del Museo permiten conocer la diversidad de artefactos utilizados y la tecnología empleada en su transformación. No obstante, cabe destacar que, como en toda colección etnográfica, queda reflejado el sesgo que dirigió la recolección de los objetos y la posterior sistematización museográfica.

El Museo del Fin del Mundo cuenta con una variada colección de instrumentos pertenecientes a los antiguos pobladores del extremo austral ameri- 
cano. Entre los artefactos se puede encontrar varios instrumentos confeccionados con fibras vegetales, madera, hueso, valva y lítico.

La totalidad del material estudiado posee tan sólo atribución genérica de procedencia geográfica $y$ en ninguno de los casos existe una atribución étnica de las piezas. La muestra se compone de dos arcos y quince astiles de madera sobre los que se llevaron a cabo tres tipos de análisis: 1 . Análisis morfológico de la totalidad de las piezas de madera, 2. Determinación taxonómica de la materia prima vegetal de los dos arcos y diez astiles y 3. Análisis morfotécnicos y dimensionales de las puntas de armas enmangadas en los astiles.

\section{ANÁLISIS MORFOLÓGICO}

El análisis morfológico de los instrumentos se basó en el registro de la longitud y diámetro de

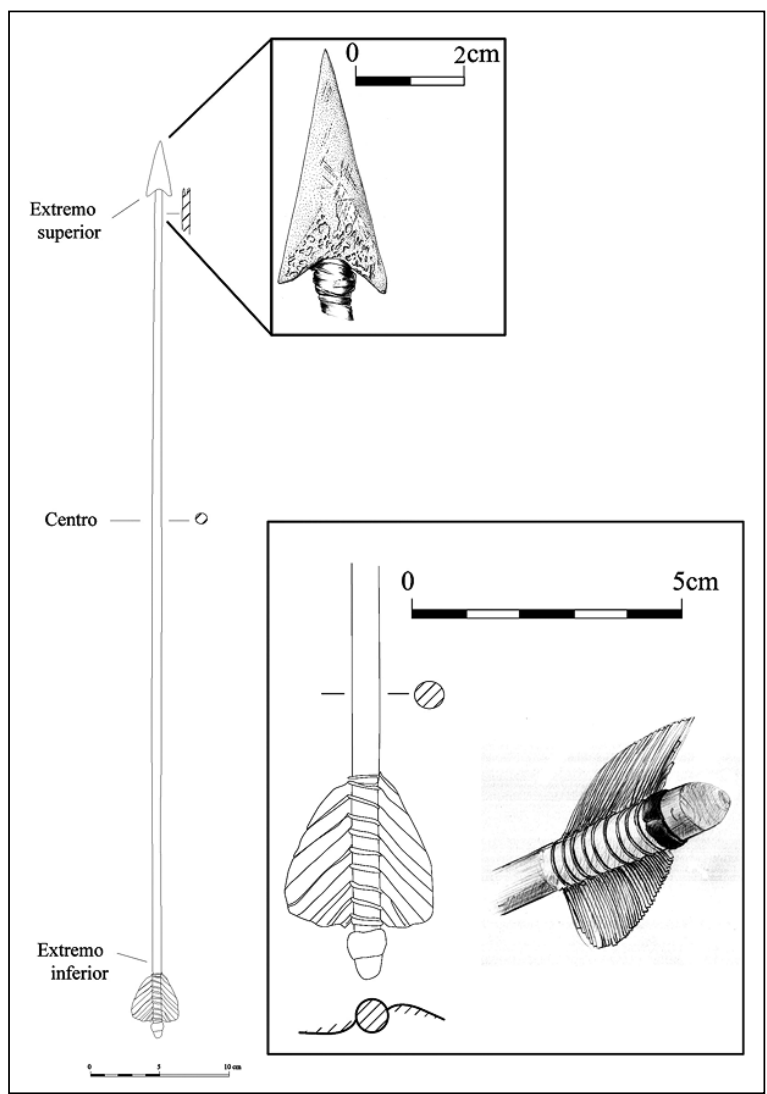

Fig. 1. Diseño de astil con indicaciones de análisis morfológico y detalle de flecha, punta y emplumado.

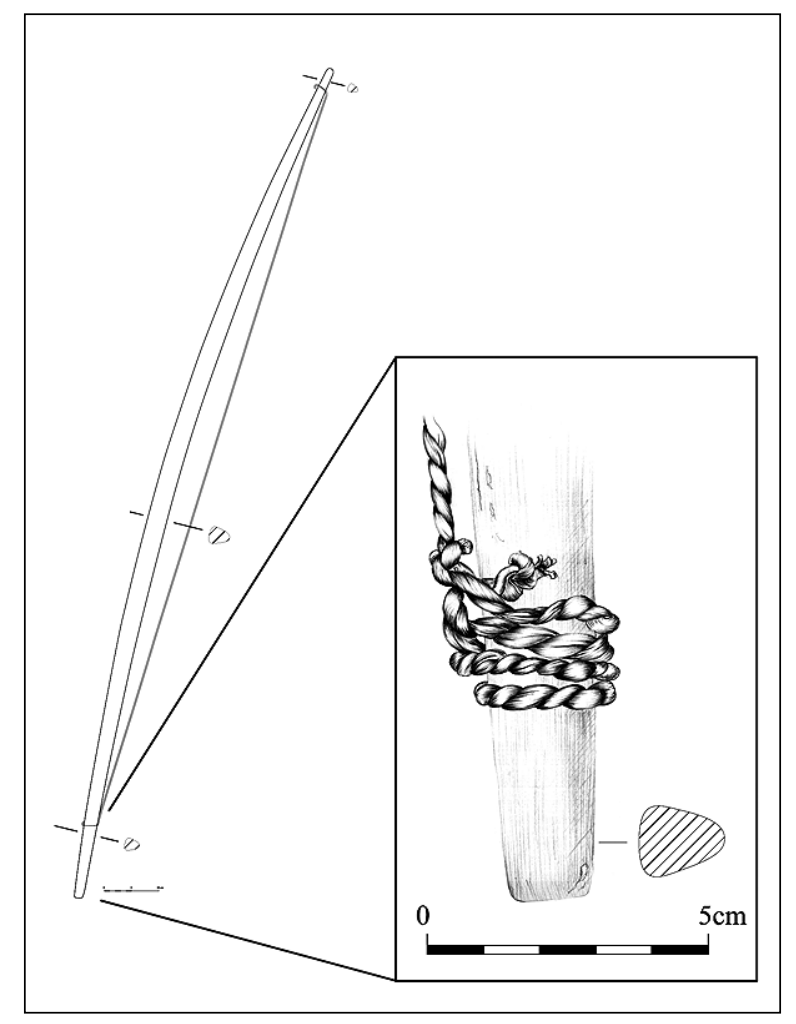

Fig. 2. Diseño de arco y detalle de atadura de cuerda.

ambos extremos -superior e inferior-y de la parte central de cada pieza (Fig. 1 y 2). Además fueron consignadas la presencia de restos de corteza, las características de la superficie del material -pulida o con marcas de descortezamiento- y los extremos de la pieza. En el caso de los astiles fue registrada la presencia de puntas de flecha o la ranura para su inserción en el extremo superior así como la presencia de emplumados y engomados de la pieza en el extremo inferior.

\section{Arcos de madera}

Las dimensiones de los arcos son bastante similares entre sí (Fig. 3a). La longitud de extremo a extremo de las piezas, oscilan entre los 1530 y $1730 \mathrm{~mm}$. La anchura máxima es de $36 \mathrm{~mm}$ en la parte central del arco (R 522) (ver Tabla 6). Los dos arcos se caracterizan por poseer los extremos directamente cortados y la disminución del diámetro general del instrumento se hace evidente en los extremos (Fig. 3b). En el plano formal, en general ambos presentan una sección almendrada y la for- 


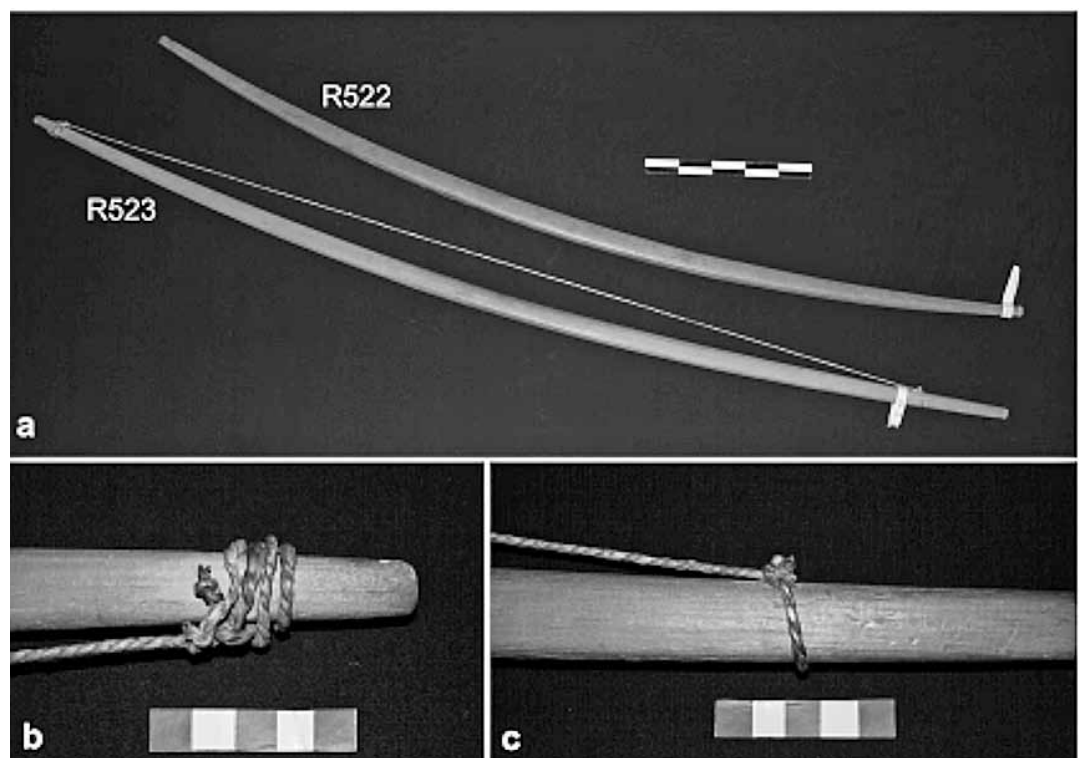

Fig. 3. a: ejemplares de arcos colección Museo del Fin del Mundo. b: Detalle del extremo cortado del arco. c: Detalle del pulido de la madera.

matización final se ha realizado mediante el pulido general de la superficie de la pieza (Fig. 3c).

La curvatura de los arcos es variable. La distancia existente entre el arco y la cuerda, así como la distancia entre la atadura y el extremo del arco, no fueron tenidas en cuenta, dado que solo uno de ellos presenta una cuerda relativamente floja -posiblemente por haber sido utilizada para colgarlo-, lo que no permite considerarla como una característica óptima para la comparación con otros casos.

Si comparamos las dimensiones de estos arcos con los estudiados por Piqué y Ratto (que fueran presentados en páginas previas: Tablas 1 y 3), observamos que la longitud se encuentran dentro de los rangos obtenidos en los análisis realizados por estas investigadoras; sólo el diámetro de la parte central es ligeramente mayor en el caso de los ejemplares del Museo del Fin del Mundo.

\section{Astiles de madera}

De los quince astiles conservados solo dos de ellos no presentan evidencia de punta de proyectil o encastre alguno, estos son los ejemplares "A" y " $D$ ", en los cuales su extremo superior esta truncado en forma perpendicular al eje de longitudinal del astil (Figura 4a; Tabla 7). El resto de los astiles presentan puntas aseguradas con tiento o bien restos de sus pedúnculos encastrados dentro de ranuras, lo que evidencia la indudable presencia de puntas hoy fracturadas. Diez de ellas fueron confeccionadas sobre hueso, dos sobre vidrio -de las cuales solo se

Tabla 6. Morfología de los Arcos de madera del Museo del Fin del Mundo.

\begin{tabular}{|c|c|c|c|c|c|c|c|c|c|c|c|c|}
\hline \multirow{2}{*}{ Arco } & \multirow{2}{*}{$\begin{array}{l}\text { Longitud } \\
\text { (1) } \mathrm{mm}\end{array}$} & \multicolumn{3}{|c|}{ Diámetro } & \multicolumn{2}{|c|}{ Características } & \multirow{2}{*}{ Sección } & \multirow{2}{*}{$\begin{array}{l}\text { Tipo de } \\
\text { soporte }\end{array}$} & \multirow{2}{*}{$\begin{array}{l}\text { Distancia } \\
\text { entre } \\
\text { cuerda y } \\
\text { arco }-\mathrm{cm}^{-}\end{array}$} & \multirow{2}{*}{$\begin{array}{l}\text { Acabados } \\
\text { superficie }\end{array}$} & \multirow{2}{*}{ Corteza } & \multirow{2}{*}{ Taxón } \\
\hline & & $\begin{array}{c}\text { Extremo } \\
\text { A mm }\end{array}$ & $\begin{array}{c}\text { Centro } \\
\mathrm{mm}\end{array}$ & $\begin{array}{c}\text { Extremo } \\
\text { B mm }\end{array}$ & $\begin{array}{c}\text { Extremo } \\
\text { A mm }\end{array}$ & $\begin{array}{c}\text { Extremo } \\
\mathrm{B} \mathrm{mm}\end{array}$ & & & & & & \\
\hline R522 & 1370 & 15 & 36 & 15 & $\begin{array}{l}\text { Cortado } \\
\text { con } \\
\text { pequeña } \\
\text { fractura }\end{array}$ & Cortado & Almendrada & $\begin{array}{l}1 / 4 \mathrm{de} \\
\text { tronco }\end{array}$ & $\begin{array}{c}\text { No posee } \\
\text { cuerda }\end{array}$ & Pulida & $\begin{array}{c}\text { No } \\
\text { presenta }\end{array}$ & $\begin{array}{c}\text { Nothofagus } \\
\text { pumilio }\end{array}$ \\
\hline R523 & 1530 & 13 & 34 & 15 & Cortado & $\begin{array}{c}\text { Cortado, } \\
\text { con } \\
\text { grietas }\end{array}$ & Almendrada & $\begin{array}{l}1 / 4 \mathrm{de} \\
\text { tronco }\end{array}$ & $\begin{array}{c}4,5 \\
\text {-no } \\
\text { presenta } \\
\text { tensión- }\end{array}$ & $\begin{array}{c}\text { Pulida con } \\
\text { marcas de } \\
\text { descortezamiento }\end{array}$ & $\begin{array}{c}\text { No } \\
\text { presenta }\end{array}$ & $\begin{array}{c}\text { Nothofagus } \\
\text { pumilio }\end{array}$ \\
\hline
\end{tabular}

(1) Largo del arco de extremo a extremo. 


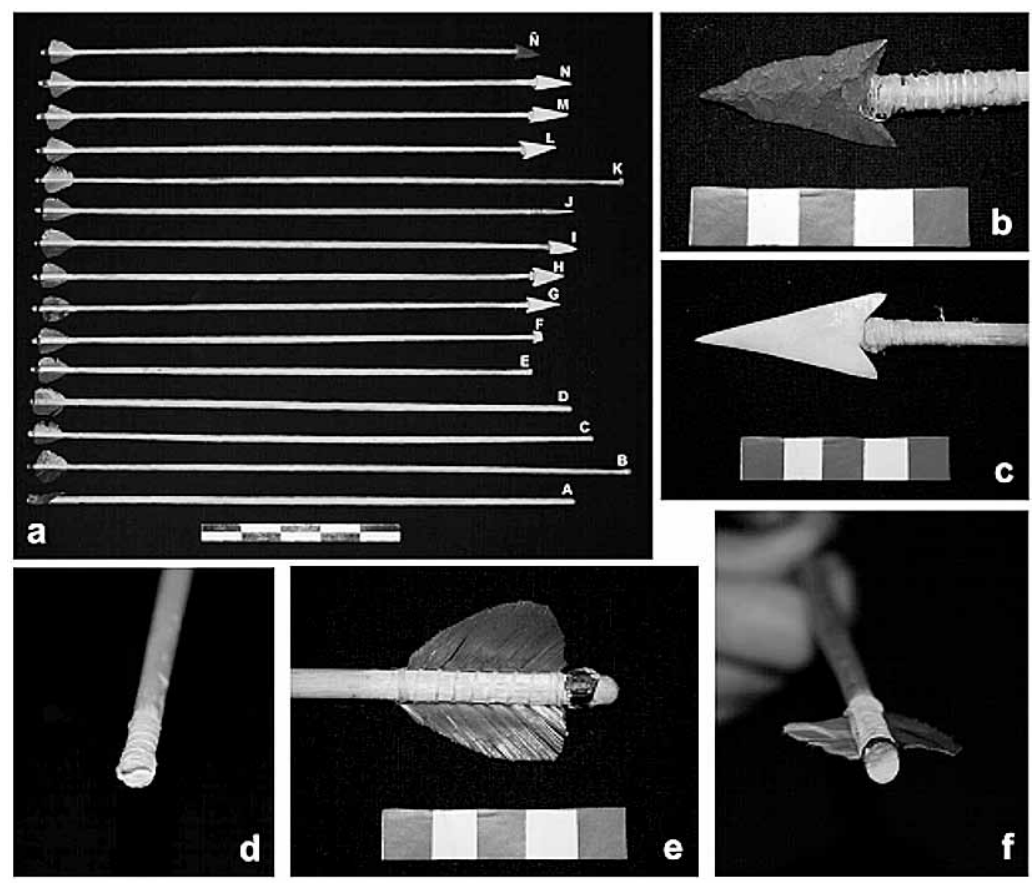

Fig 4. a: Ejemplares flechas colección Museo del Fin del Mundo. b: Flecha Ñ, detalle punta lítica. c: Flecha G, detalle punta ósea. d: Flecha C: Detalle ranura para encastre. e: Flecha H, detalle de emplumado. F: Flecha G: Detalle emplumado.

conservan sus pedúnculos- y solo una sobre roca (Figura 4b-c-d; Tabla 7). Todas las piezas poseen emplumado en su extremo inferior, en general en buen estado de conservación, con la excepción de ejemplar "A" el cual se encuentra parcialmente deteriorado. En posición posterior al emplumado, todos los ejemplares presentan un "anillo" de sustancia negra similar a la brea, que denominamos "engomado", cuya funcionalidad desconocemos, pero que posiblemente tenga relación con la acción de asir la flecha en forma más efectiva en el momento de mayor tensión del arco.

En forma más o menos marcada, pero en todos los casos, el emplumado presenta la característica descripta por Prieto, para ejemplares de la colección del Museo Regional "Mayorino Borgatello" de Punta Arenas (Prieto 1987). Esta disposición de los estabilizadores se caracteriza por presentar una forma helicoidal, que determinaba la rotación y estabilidad durante la trayectoria de vuelo del proyectil. En las aves voladoras las plumas primarias presentan una sección transversal curva, con una cara inferior cóncava y una superior convexa. Para la confección de estos estabilizadores se seleccionaron segmentos de plumas de este tipo y fueron dispuestas con sus caras cóncavas orientadas en forma alternada, una mirando para cada lado (Fig. $4 e-f)$.

Los astiles tienen un perfil rectilíneo y ninguno de ellos conserva restos de corteza. Las trazas de los instrumentos utilizados para el descortezamiento y desbastado de la madera son inexistentes ya que la superficie de todas las piezas se encuentra perfectamente pulida. Las características morfológicas registradas muestran un importante grado de estandarización de los astiles.

La longitud de los 15 astiles varía entre 635 y $772 \mathrm{~mm}$. El astil "Ñ" es el más corto mientras que el astil "K" es el de mayor longitud; en ambos casos las puntas enmangadas no corresponden a piezas óseas. El diámetro máximo del extremo superior del conjunto oscila entre 5 y $8 \mathrm{~mm}$, la parte central entre 8 y $10 \mathrm{~mm}$ y el extremo inferior entre 5 y 7 $\mathrm{mm}$. El astil de mayor longitud es el "B" con 770 $\mathrm{mm}$. de largo y se encuentra dentro del grupo de los que no presentan puntas.

La comparación de las características dimensionales entre este conjunto y los analizados por otras investigadoras posibilita realizar una serie de observaciones. Cabe aclarar que los procesos 
Tabla 7. Morfología de los astiles de madera del Museo del Fin del Mundo.

\begin{tabular}{|c|c|c|c|c|c|c|c|c|c|c|c|c|}
\hline \multirow[b]{2}{*}{ Astil } & \multirow[b]{2}{*}{ Punta } & \multirow[b]{2}{*}{$\begin{array}{l}\text { Longitud } \\
\text { del astil }\end{array}$} & \multirow[b]{2}{*}{$\begin{array}{l}\text { Longitud } \\
\text { de la pieza }\end{array}$} & \multicolumn{3}{|c|}{ Diámetro } & \multirow[b]{2}{*}{$\begin{array}{l}\text { Extremo } \\
\text { anterior }\end{array}$} & \multirow[b]{2}{*}{$\begin{array}{l}\text { Extremo } \\
\text { posterior }\end{array}$} & \multirow[b]{2}{*}{ 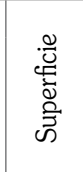 } & \multirow[b]{2}{*}{ Ũ } & \multirow[b]{2}{*}{ 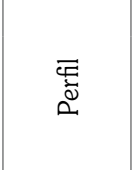 } & \multirow{2}{*}{ 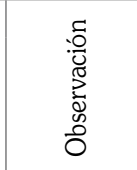 } \\
\hline & & & & $\begin{array}{c}\text { Extremo } \\
\text { anterior } \\
\text { (mm) }\end{array}$ & $\begin{array}{c}\text { Centro } \\
(\mathrm{mm})\end{array}$ & $\begin{array}{l}\text { Extremo } \\
\text { posterior } \\
(\mathrm{mm})\end{array}$ & & & & & & \\
\hline A & No presenta & 695 & - & 8 & 10 & 7 & Cortado & $\begin{array}{l}\text { Cortado, } \\
\text { con restos de } \\
\text { emplumado }\end{array}$ & Pulida & $\begin{array}{c}\text { No } \\
\text { presenta }\end{array}$ & Rectilíneo & $\begin{array}{l}\text { Marcas de } \\
\text { fuego }\end{array}$ \\
\hline B & $\begin{array}{l}\text { Vidrio solo } \\
\text { pedúnculo }\end{array}$ & 770 & - & 5 & 8 & 6 & $\begin{array}{c}\text { Ranura } \\
\text { para flecha }\end{array}$ & $\begin{array}{l}\text { Engomado + } \\
\text { emplumado }\end{array}$ & Pulida & $\begin{array}{c}\text { No } \\
\text { presenta }\end{array}$ & Rectilíneo & - \\
\hline $\mathrm{C}$ & $\begin{array}{c}\text { Solo } \\
\text { pedúnculo }\end{array}$ & 720 & - & 6 & 8 & 5 & $\begin{array}{c}\text { Ranura } \\
\text { para flecha }\end{array}$ & $\begin{array}{l}\text { Engomado + } \\
\text { emplumado }\end{array}$ & Pulida & $\begin{array}{c}\text { No } \\
\text { presenta }\end{array}$ & Rectilíneo & - \\
\hline D & No presenta & 690 & - & 7 & 7 & 7 & Cortado & Emplumado & Pulida & $\begin{array}{c}\text { No } \\
\text { presenta }\end{array}$ & Rectilíneo & - \\
\hline E & $\begin{array}{l}\text { Hueso solo } \\
\text { pedúnculo }\end{array}$ & 645 & - & 6 & 9 & 6 & Quebrado & Emplumado & Pulida & $\begin{array}{c}\text { No } \\
\text { presenta }\end{array}$ & Rectilíneo & - \\
\hline $\mathrm{F}$ & $\begin{array}{l}\text { Hueso } \\
\text { quebrada }\end{array}$ & 660 & 670 & 6 & 9 & 7 & $\begin{array}{c}\text { Punta } \\
\text { quebrada }\end{array}$ & Emplumado & Pulida & $\begin{array}{c}\text { No } \\
\text { presenta }\end{array}$ & Rectilíneo & $\begin{array}{c}\text { Grieta } \\
\text { longitudina }\end{array}$ \\
\hline G & $\begin{array}{l}\text { Hueso } \\
\text { completa }\end{array}$ & 645 & 685 & 6 & 8 & 6 & Punta & Emplumado & Pulida & $\begin{array}{c}\text { No } \\
\text { presenta }\end{array}$ & Rectilíneo & - \\
\hline $\mathrm{H}$ & $\begin{array}{l}\text { Hueso } \\
\text { completa }\end{array}$ & 650 & 690 & 5 & 8 & 6 & Punta & Emplumado & Pulida & $\begin{array}{c}\text { No } \\
\text { presenta }\end{array}$ & Rectilíneo & - \\
\hline I & $\begin{array}{l}\text { Hueso } \\
\text { completa }\end{array}$ & 675 & 710 & 6 & 9 & 7 & Punta & Emplumado & Pulida & $\begin{array}{c}\text { No } \\
\text { presenta }\end{array}$ & Rectilíneo & - \\
\hline $\mathrm{J}$ & $\begin{array}{l}\text { Hueso } \\
\text { completa }\end{array}$ & 670 & 700 & 7 & 9 & 6 & Punta & Emplumado & Pulida & $\begin{array}{c}\text { No } \\
\text { presenta }\end{array}$ & Rectilíneo & - \\
\hline $\mathrm{K}$ & $\begin{array}{l}\text { Vidrio solo } \\
\text { pedunculo }\end{array}$ & 772 & - & 5 & 8 & 5 & $\begin{array}{c}\text { Ranura } \\
\text { para flecha }\end{array}$ & Emplumado & Pulida & $\begin{array}{c}\text { No } \\
\text { presenta }\end{array}$ & Rectilíneo & - \\
\hline $\mathrm{L}$ & $\begin{array}{l}\text { Hueso } \\
\text { completa }\end{array}$ & 643 & 684 & 6 & 8 & 6 & Punta & Emplumado & Pulida & $\begin{array}{c}\text { No } \\
\text { presenta }\end{array}$ & Rectilíneo & - \\
\hline M & $\begin{array}{l}\text { Hueso } \\
\text { completa }\end{array}$ & 655 & 705 & 6 & 9 & 7 & Punta & Emplumado & Pulida & $\begin{array}{c}\text { No } \\
\text { presenta }\end{array}$ & Rectilíneo & - \\
\hline $\mathrm{N}$ & $\begin{array}{l}\text { Hueso } \\
\text { completa }\end{array}$ & 660 & 710 & 7 & 9 & 7 & Punta & Emplumado & Pulida & $\begin{array}{c}\text { No } \\
\text { presenta }\end{array}$ & Rectilíneo & - \\
\hline$\tilde{\mathrm{N}}$ & $\begin{array}{l}\text { Litico } \\
\text { completa }\end{array}$ & 635 & 665 & 5 & 8 & 6 & Punta & Emplumado & Pulida & $\begin{array}{c}\text { No } \\
\text { presenta }\end{array}$ & Rectilíneo & - \\
\hline
\end{tabular}

de formación de estas colecciones no están claros y que las divisiones entre cada uno de ellas están relacionadas con la disponibilidad y/o el acceso a esas colecciones y no necesariamente con criterios regionales, temporales o étnicos. No obstante es interesante explorar algunas tendencias entre cada uno de los conjuntos para evaluar la variabilidad entre los astiles fueguinos.

En primer lugar, en lo que respecta a la longitud hemos constatado que la colección del Museo del
Fin del Mundo presenta mayor variación en lo que respecta a la longitud de las piezas tal como lo indican el desvío estándar y el coeficiente de variación (Tabla 8); este conjunto exhibe medidas máximas y mínimas mayores que el resto de los conjuntos considerados. Sin embargo, si aplicamos el test de rangos múltiples a cada uno de ellos tomados de a pares observamos que no existen diferencias significativas en las medias (con un 95\% de confianza) entre la mayoría de ellos, con excepción de la colección del Museo de La Plata

Tabla 8. Estadística descriptiva de la longitud de los astiles de diferentes colecciones etnográficas.

\begin{tabular}{|l|c|c|c|c|c|c|}
\hline Colecciones & $\mathrm{n}$ & Media & Desviación St & Mínimo & Máximo & Coeficiente de variación \\
\hline CMFM & 15 & 679 & 43,73 & 635,0 & 772,0 & 6,44 \\
\hline CMLP & 4 & 731,25 & 25,94 & 700,0 & 755,0 & 3,55 \\
\hline CMLPME & 19 & 680,52 & 30,59 & 640,0 & 741,0 & 4,49 \\
\hline CMP & 9 & 683,88 & 23,29 & 640,0 & 720,0 & 3,40 \\
\hline
\end{tabular}




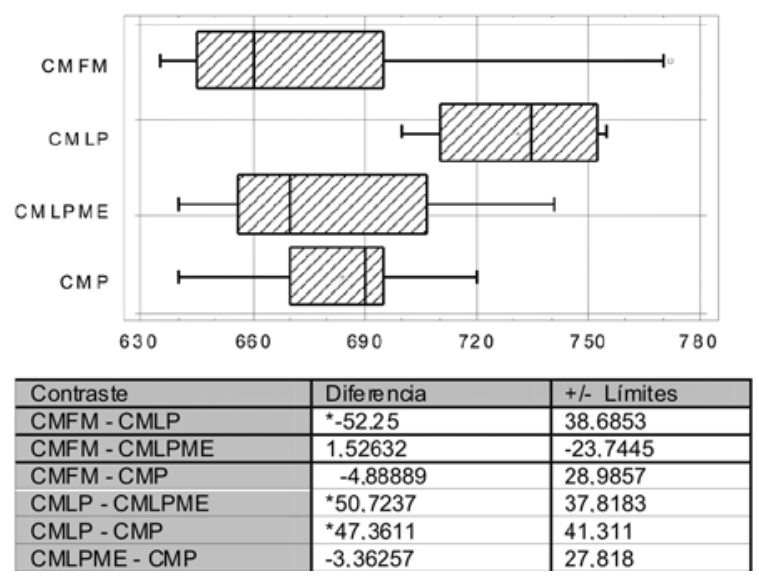

Fig. 5. Arriba: Diagrama de caja y arbotante de la longitud de los astiles. Abajo: Test de rangos múltiples entre los distintos conjuntos analizados.

Nota: * denota una diferencia estadística definitiva.

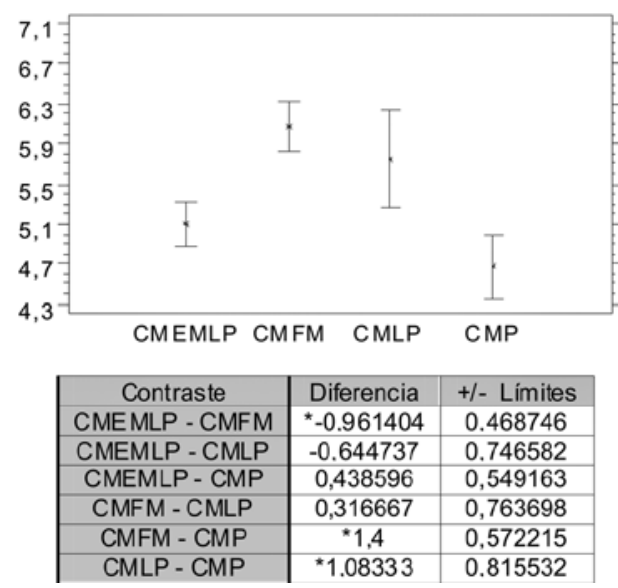

Fig. 6. Arriba: Diagrama de medidas de tendencia central del diámetro anterior de los astiles. Abajo: Test de rangos múltiples entre los distintos conjuntos analizados.

Nota: * denota una diferencia estadística definitiva. analizado por Caruso (2008) en que los ejemplares son más largos que el resto (Fig. 5). Es posible que esta diferencia obedezca al tamaño de la muestra.

En cuanto a los diámetros de los astiles, fueron consideradas las medidas del extremo anterior, del centro y del extremo posterior. En el primero de los casos, es la colección del Museo del Fin del Mundo una de las que presenta mayor variabilidad interna (Tabla 9) sólo superada por la colección del Museo de La Plata analizada por Caruso (2008). En este caso el tamaño de la muestra no parece ser un factor de peso en estos resultados. La correlación entre el tamaño de la muestra y el coeficiente de variación muestra un valor bajo y negativo: $r=-0,66$. Más aún, si comparamos las medias de los distintos conjuntos puede demostrarse diferencias significativas entre la colección del Museo del Fin del Mundo con respecto a la del Museo Pigorini y la colección Museo de La Plata/ Museo Etnográfico (ver Fig. 6). Las mismas tendencias se mantienen para el diámetro de la porción central y posterior (Tablas 10 y 11, Figs. 7 y 8) en las que la colección del Museo del Fin del Mundo presenta valores más elevados que el resto.

\section{ANÁLISIS ARQUEOBOTÁNICO}

El análisis arqueobotánico consistió en la toma de muestras de algunas de las piezas (dos arcos y diez astiles) y en la identificación de la especie leñosa con la cual fueron confeccionadas cada una de ellas.

La identificación de la madera se realizó a partir de la observación de la estructura anatómica

Tabla 9. Estadística descriptiva del diámetro anterior de los astiles de diferentes colecciones etnográficas.

\begin{tabular}{|l|c|c|c|c|c|c|}
\hline Colecciones & $\mathrm{N}$ & Media & Desviación St & Mínimo & Máximo & Coeficiente de variación \\
\hline CMFM & 15 & 6,01 & 0,88 & 5,0 & 8 & 14,57 \\
\hline CMLP & 4 & 5,75 & 0,96 & 5,0 & 7,0 & 16,65 \\
\hline CMLPME & 19 & 5,10 & 0,46 & 5,0 & 7,0 & 8,99 \\
\hline CMP & 9 & 4,67 & 0,50 & 4,0 & 5,0 & 10,71 \\
\hline
\end{tabular}

Tabla 10. Estadística descriptiva del diámetro central de los astiles de diferentes colecciones etnográficas. Se excluye la colección del Museo de La Plata analizada por Caruso (2008) porque la medida es constante.

\begin{tabular}{|l|c|c|c|c|c|c|}
\hline Colecciones & $\mathrm{N}$ & Media & Desviación St & Mínimo & Máximo & Coeficiente de variación \\
\hline CMFM & 15 & 8,46667 & 0,743223 & 7,0 & 10,0 & 8,77823 \\
\hline CMLPME & 19 & 7,13158 & 0,522869 & 6,0 & 8,5 & 7,33174 \\
\hline CMP & 9 & 7,11111 & 0,600925 & 6,0 & 8,0 & 8,45051 \\
\hline
\end{tabular}


Tabla 11. Estadística descriptiva del diámetro posterior de los astiles de diferentes colecciones etnográficas.

\begin{tabular}{|l|c|c|c|c|c|c|}
\hline Colecciones & $\mathrm{n}$ & Media & Desviación St & Mínimo & Máximo & Coeficiente de variación \\
\hline CMFM & 15 & 6,26667 & 0,703732 & 5,0 & 7,0 & 11,2298 \\
\hline CMLP & 4 & 5,5 & 0,57735 & 5,0 & 6,0 & 10,4973 \\
\hline CMLPME & 19 & 4,94737 & 0,229416 & 4,0 & 5,0 & 4,63713 \\
\hline CMP & 9 & 4,11111 & 0,600925 & 3,0 & 5,0 & 14,6171 \\
\hline
\end{tabular}

de sus tres planos: transversal, longitudinal radial y longitudinal tangencial. Cada uno de estos planos posee unas características y estructura variable según la especie. Este método es ampliamente utilizado en el campo de la arqueobotánica (Vernet 1973, Chabal 1982, entre otros) y permite estudiar un gran número de muestras en poco tiempo.

La toma de muestras consistió en la extracción de láminas delgadas de cada uno de los tres planos naturales de la madera con la ayuda de un instrumento cortante. Las muestras fueron visualizadas a través de un microscopio Zeizz "Axioskop 40" y comparadas con muestras de referencia de madera actual. El material de referencia fue colectado por L. Caruso Fermé en diversos sitios de la Patagonia argentina y chilena.

-Berberis buxifolia -calafate-: Camino de los presos (Ushuaia) y costa del canal Beagle -Prov. Tierra del Fuego-; Valdivia - Región de Los Ríos, Chile-; Bariloche -Prov. Río Negro- y Estancia Pali Aike; Cueva Buitreras; El Calafate -Prov. Santa Cruz-.

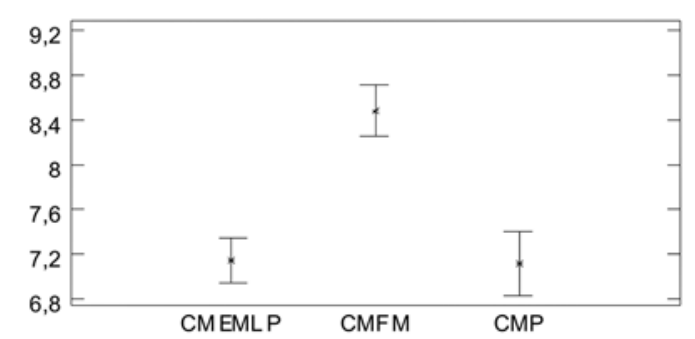

\begin{tabular}{|c|c|c|}
\hline Contraste & Diferencia & $+/$ Limites \\
\hline CMEMLP - CMFM & $*-1.33509$ & 0.435153 \\
\hline CMEMLP - CMP & 0.0204678 & 0.50980 \\
\hline CMFM - CMP & 1.35556 & $* 0.531207$ \\
\hline
\end{tabular}

Fig. 7. Arriba: Diagrama de medidas de tendencia central del diámetro central de los astiles. Abajo: Test de rangos múltiples entre los distintos conjuntos analizados.

Nota: * denota una diferencia estadística definitiva.
-Ribes magellanicus. -parrilla-: canal Beagle -Prov. Tierra del Fuego- y Río Turbio -Prov. Santa CruzEl material correspondiente a Nothofagus proviene de distintas zonas según la especie.

-Nothofagus antarctica -ñire-: San Martin de los Andes -Prov. Neuquén-; Norte del Lago Fagnano -Prov. de Tierra del Fuego- y Río Turbio -Prov. Santa Cruz-.

-Nothofagus dombeyi (Mirb.) Oerts -coihue-: Lago Gutiérrez -Prov. Rio Negro- y Valdivia -Región de Los Ríos, Chile-.

-Nothofagus betuloides -guindo- Ushuaia -Tierra del Fuego-.

-Nothofagus nervosa-alpina (Phil.) Dimitri \& Milano -raulí-: San Martin de los Andes -Prov. Neuquén- y Valdivia -Región de Los Ríos, Chile-.

-Nothofagus pumilio (Poepp. \& Endl.) Krasser -lenga-: Cerro Catedral -Prov. Río Negro-; Monte Martial -Prov. de Tierra del Fuego- y Río Turbio -Prov. Sta. Cruz-.

-Nothofagus oblicua (Mirb.) Oerst. -roble-: Valdivia -Región de Los Ríos, Chile-

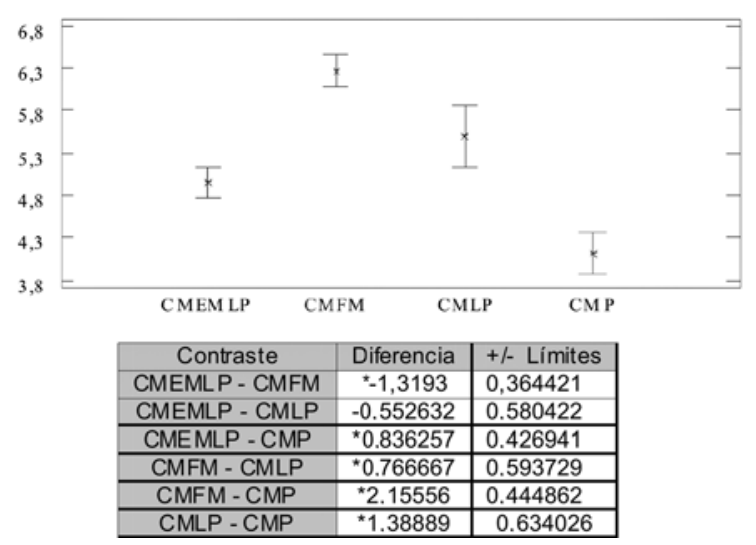

Fig. 8. Arriba: Diagrama de medidas de tendencia central del diámetro posterior de los astiles. Abajo: Test de rangos múltiples entre los distintos conjuntos analizados. Nota: * denota una diferencia estadística definitiva. 

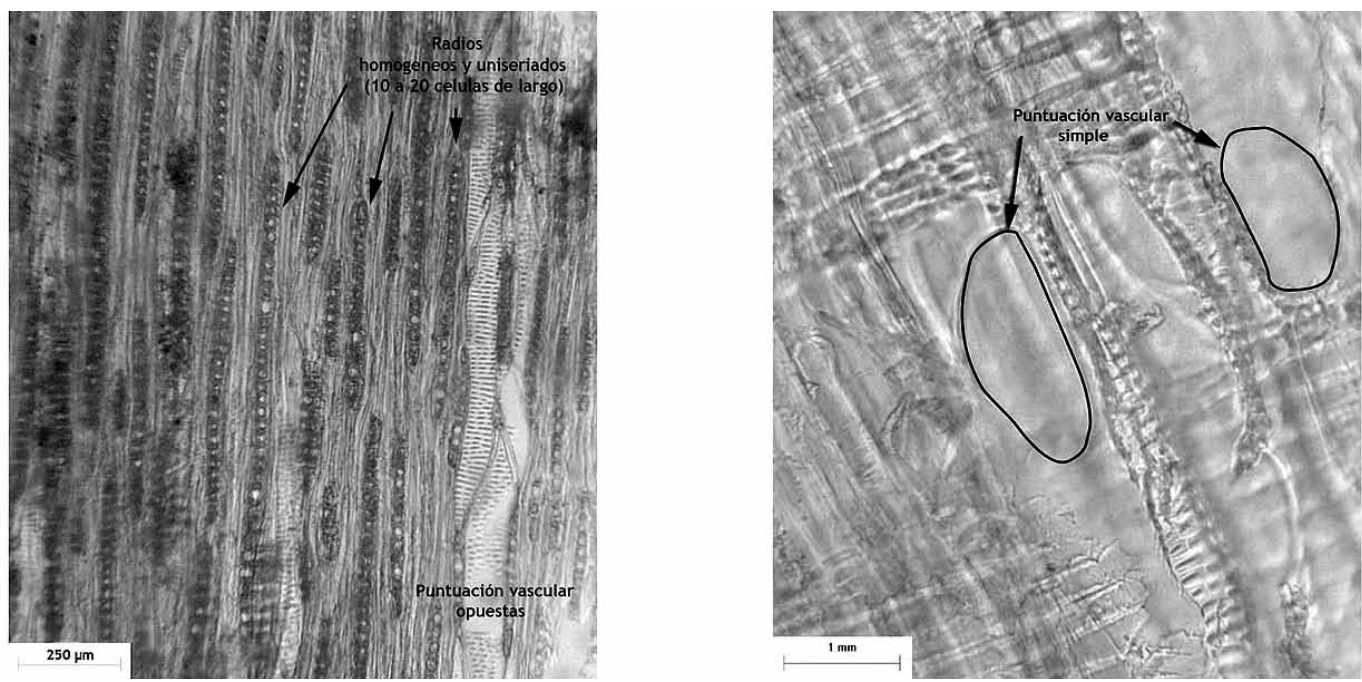

Fig. 9. Izquierda, Nothofagus sp. Corte longitudinal tangencial x 100 (Arco R523); derecha, Nothofagus sp. corte longitudinal radial x 250 (Arco R522).

\section{RESULTADOS}

Arcos

En el caso de los dos arcos estudiados, la materia prima leñosa utilizada para su confección ha sido la misma. Se trata de Nothofagus sp. Son tres las especies del género Nothofagus que conforman el bosque andino patagónico del sur de Argentina y Chile $-N$. pumilio; $N$. betuloides y $N$. antarctica-

Descripción anatómica microscópica de la madera de los dos arcos identificada como Nothofagus $s p$ :

-Corte transversal: La porosidad de la madera es difusa. Los anillos de crecimiento son visibles y ondulados. Los vasos se encuentran aislados y agrupados ( 2 a 4 poros) con una orientación radial.

-Corte longitudinal tangencial: Radios unicelulares, con una altura de 400 a $600 \mu \mathrm{m} \mathrm{(10} \mathrm{a}$ 20 células).

-Corte longitudinal radial: Los radios son homogéneos y los vasos presentan perforaciones simples y puntuaciones opuestas y escaleriformes (Fig. 9).

\section{Astiles}

En el caso de los diez astiles estudiados, el análisis taxonómico puso en evidencia la utilización de dos tipos de madera para la confección de estos instrumentos: Berberis sp y Ribes magellanicus (tabla 12) En ambos casos se trata de una materia prima local.

Son varias las especies del género Berberis que crecen en los bosques andino-patagónicos. En general estas especies se desarrollan como arbusto y solo excepcionalmente en forma de pequeños arboles. Posee hojas en fascículos y espinas tripartitas. Sus bayas son de color negro azulado, florece en primavera austral y fructifica en verano (Moore 1983, Correa 1998, Rapoport 2003, Guerrido et al 2007, Barthelemy 2008).

La similitud de las características anatomía microscópicas de la madera de las especies pertenecientes al género Berberis hace difícil su identificación a nivel microscópico, por esta razón la identificación se realizado a nivel de género. Es el mismo caso para el género Nothofagus, sin embargo debe destacarse que Nothofagus pumilio posee una característica anatómica microscópica que permite su identificación entre las otras especies de Nothofagus.

Tabla 12. Determinación taxonómica de los astiles de madera del Museo del Fin del Mundo.

\begin{tabular}{|c|c|c|c|}
\hline Astil & Taxón & Astil & Taxón \\
\hline A & Berberis $s p$. & F & Berberis $s p$. \\
\hline B & Berberis $s p$. & G & Berberis $s p$. \\
\hline C & Ribes magellanicus & H & Berberis $s p$. \\
\hline D & Berberis $s p$. & I & Ribes magellanicus \\
\hline E & Ribes magellanicus & J & Berberis $s p$. \\
\hline
\end{tabular}


La madera de los astiles identificada como Berberis sp. presenta las siguientes características anatómicas microscópicas:

-Corte Transversal: Madera de porosidad difusa. Los vasos se encuentran aislados o agrupados con una disposición tangencial y radial. Parénquima apotraqueal difuso.

-Corte longitudinal tangencial: Los radios son multiseriados (3 a 6 series).

-Corte longitudinal radial: Los radios son heterogéneos a homogéneos. Los vasos presentan perforaciones simples y puntuaciones vasculares alternas y opuestas. Presencia de engrosamientos espiralados (Fig. 10).

La especie del género Ribes que habita los bosques andino-patagónicos de Chile y Argentina es Ribes magellanicus. Se trata de un arbusto caducifolio ramificado con corteza gris oscura. Sus hojas son simples de borde irregular aserrado con 3 a 5 lóbulos. Los frutos son bayas de color negro que florecen a inicio de la primavera austral y fructifican a fines de primavera y durante verano (Moore 1983, Correa 1998, Rapoport 2003, Guerrido et al 2007, Barthelemy 2008).

Las características anatómicas microscópicas de la madera identificada como Ribes magellanicus son las siguientes:

- Corte Transversal: Madera de porosidad difusa a semiporosa. Los vasos se disponen en bandas tangenciales.

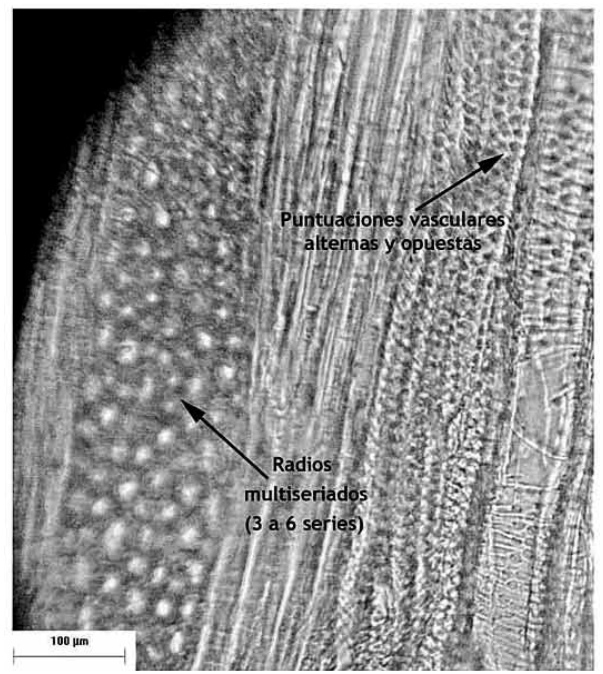

-Corte longitudinal tangencial: Radios uniseriados (2-6 células de altura) y multiseriados (4 a 14 series).

-Corte longitudinal radial: Los radios son heterogéneos. Los vasos presentan perforaciones oblicuas y escaleriformes (9-15 barras). Las puntuaciones vasculares son alternas y opuestas. (Fig. 11)

Las descripciones anatómicas de la madera antes mencionadas también pueden ser consultadas en distintos trabajos arqueobotanicos (Solari 1992-1993-1994, Piqué 1999, Ancíbor et al. 2002, Marconetto 2002) y trabajos de anatomía vegetal (Ribera 1973-2002, Inside Wood, 2004-en adelante-, Pujana et al 2008).

\section{Características tecno-morfológicas de las puntas}

Las puntas enmangadas en los astiles de la colección del Museo del Fin del mundo fueron analizadas siguiendo los criterios de Orquera y Piana (1986) y el modelo de Ratto (2003). Tal como se dijo más arriba, la mayoría de las puntas, 10 en total, fueron confeccionadas sobre hueso: siete se encuentran enteras y el resto fragmentadas. En lo que respecta a la identificación taxonómica, es posible determinar que la punta $J$ fue confeccionada sobre un fragmento de cara posterior, medial, de diáfisis de metapodio de guanaco, dado que conserva dos forámenes característicos de estos elementos anatómicos. Del resto de los ejemplares, no es posible

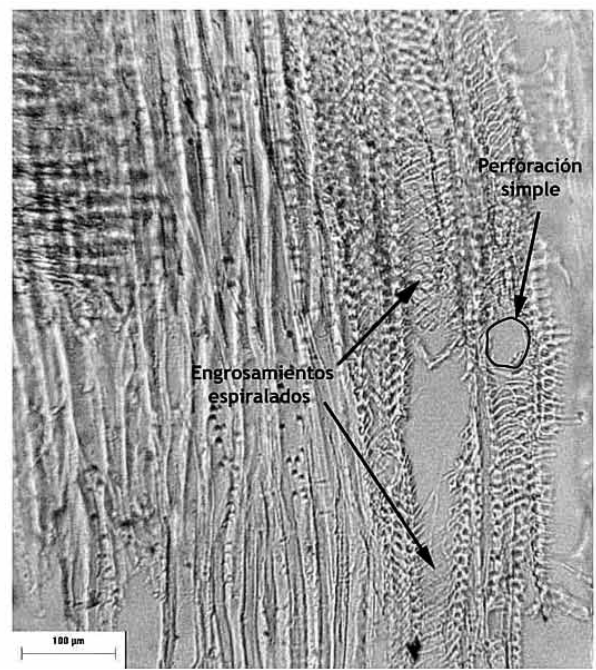

Fig. 10. Izquierda, Berberis sp. corte longitudinal tangencial x 250 (Astil F); derecha Berberis sp. corte longitudinal tangencial x250 (Astil B). 

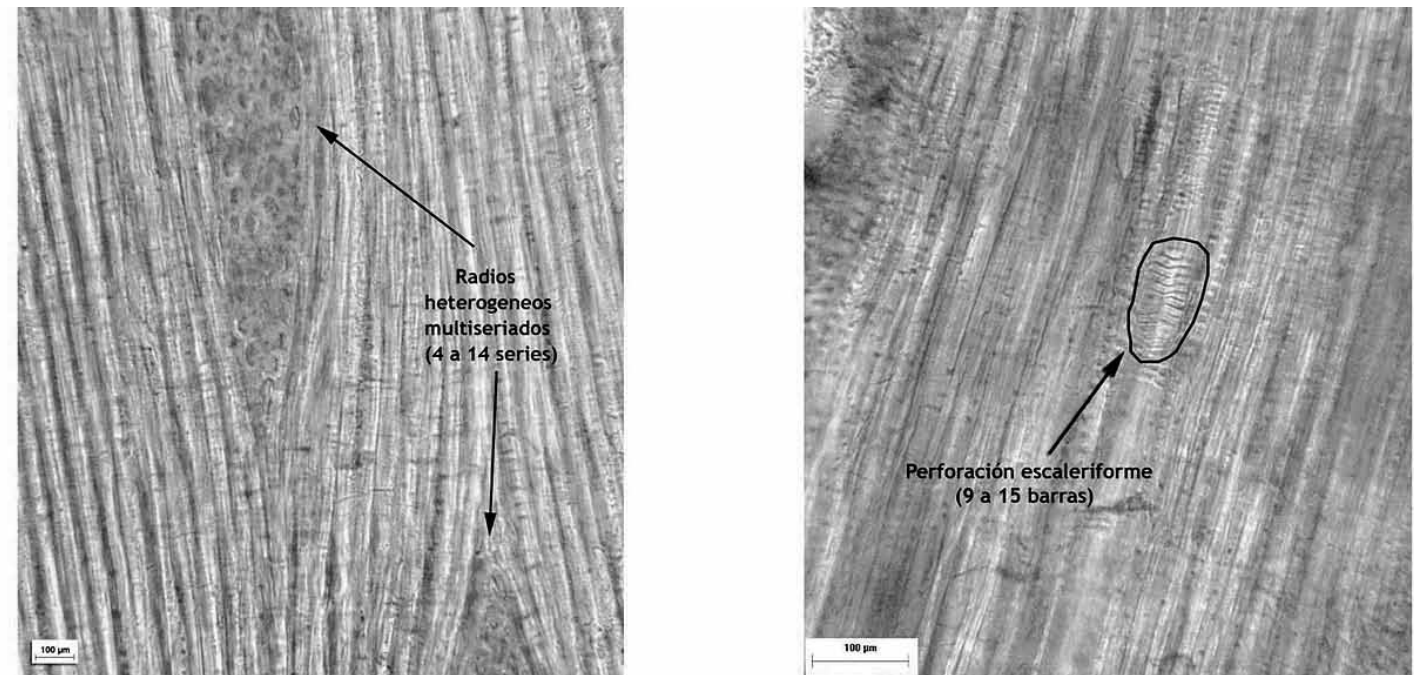

Fig. 11. Izquierda, Ribes magellanicus. corte longitudinal tangencial x 100 (Astil E); derecha, Ribes magellanicus corte longitudinal tangencial x 250 (astil C).

realizar una determinación más específica dado que en ninguno se observa algún rasgo anatómico diagnostico. No obstante, las puntas completas están confeccionadas sobre fragmentos de hueso cortical, macizo y muy denso, compatible con la estructura de las diáfisis de huesos largos de camélidos; lo que sumado a la determinación del ejemplar J, sugiere que el resto también estarían manufacturadas sobre fragmentos de diáfisis de huesos largos de guanaco. La técnica de producción consistió en el desbate del hueso mediante el empleo de algún instrumento metálico y la pulimentación posterior de la superficie.

La única punta lítica se encuentra entera y fue manufacturada sobre riolita metamorfizada de origen local, material que ha sido utilizado frecuentemente para la producción de instrumentos por parte de los grupos cazadores-recolectores fueguinos. El resto son ejemplares de vidrio de los que sólo se conserva el pedúnculo inserto en el astil.

Las piezas enteras presentan limbo triangular, pedúnculo diferenciado y aletas. En general el diseño es similar a las puntas líticas recuperadas en contextos arqueológicos y de aquellas ilustradas por la literatura etnográfica. En la tabla 13 se presentan las características dimensionales de la puntas junto con las variables consideradas para la asignación funcional de los cabezales líticos (se excluyen las piezas fragmentadas).

De forma coincidente con las expectativas del modelo de asignación funcional, estos ejemplares presentan un índice de refuerzo bajo y una aero-

Tabla 13. Características dimensionales y variables de asignación funcional de las puntas de la colección del Museo del Fin del Mundo.

\begin{tabular}{|c|c|c|c|c|c|c|c|c|c|c|c|}
\hline $\begin{array}{c}\mathrm{N}^{\circ} \\
\text { invent }\end{array}$ & $\begin{array}{c}\text { Largo } \\
(\mathrm{max})\end{array}$ & $\begin{array}{c}\text { Ancho } \\
(\mathrm{max})\end{array}$ & $\begin{array}{c}\text { Espesor } \\
\text { (max) }\end{array}$ & Tamaño & $\begin{array}{c}\text { Relación largo/ } \\
\text { ancho (total) }\end{array}$ & $\begin{array}{c}\text { Relación } \\
\text { ancho/ } \\
\text { espesor }\end{array}$ & $\begin{array}{c}\text { Superficie de } \\
\text { contacto con el } \\
\text { fluido (en mm2) }\end{array}$ & $\begin{array}{c}\text { Largo } \\
\text { del } \\
\text { limbo }\end{array}$ & $\begin{array}{c}\text { Ancho de la Superficie de } \\
\text { base (ped) }\end{array}$ & $\begin{array}{c}\text { Índice de } \\
\text { refuerzo } \\
\text { refuerzo }\end{array}$ \\
\hline $\mathrm{G}$ & 41 & 20 & 2 & $\mathrm{MD}$ & 2 & 10 & 410 & 39 & $\mathrm{ND}$ & 0,1 & $\mathrm{MB}$ \\
\hline $\mathrm{H}$ & 44 & 23 & 2 & $\mathrm{MD}$ & 1,9 & 11,5 & 506 & 41 & 0,9 & 0,08 & $\mathrm{MB}$ \\
\hline $\mathrm{I}$ & 39 & 16 & 2 & $\mathrm{PQ}$ & 2,4 & 8 & 312 & 35 & $\mathrm{ND}$ & 0,12 & $\mathrm{MB}$ \\
\hline $\mathrm{J}$ & 39 & 13 & 2 & $\mathrm{PQ}$ & 3 & 6,5 & 253,5 & 33 & $\mathrm{ND}$ & 0,15 & $\mathrm{MB}$ \\
\hline $\mathrm{L}$ & 46 & 20 & 2 & $\mathrm{MD}$ & 2,3 & 10 & 460 & 41 & $\mathrm{ND}$ & 0,1 & $\mathrm{MB}$ \\
\hline $\mathrm{M}$ & 48 & 20 & 3 & $\mathrm{MD}$ & 2,4 & 6,7 & 480 & 43 & $\mathrm{ND}$ & 0,15 & $\mathrm{MB}$ \\
\hline $\mathrm{N}$ & 39 & 20 & 3 & $\mathrm{MD}$ & 2,0 & 6,7 & 390 & 36 & $\mathrm{ND}$ & 0,15 & $\mathrm{MB}$ \\
\hline$\tilde{N}$ & 48 & 16 & 2 & $\mathrm{MD}$ & 3,0 & 8,0 & 384 & 44 & $\mathrm{ND}$ & 0,13 & $\mathrm{MB}$ \\
\hline
\end{tabular}




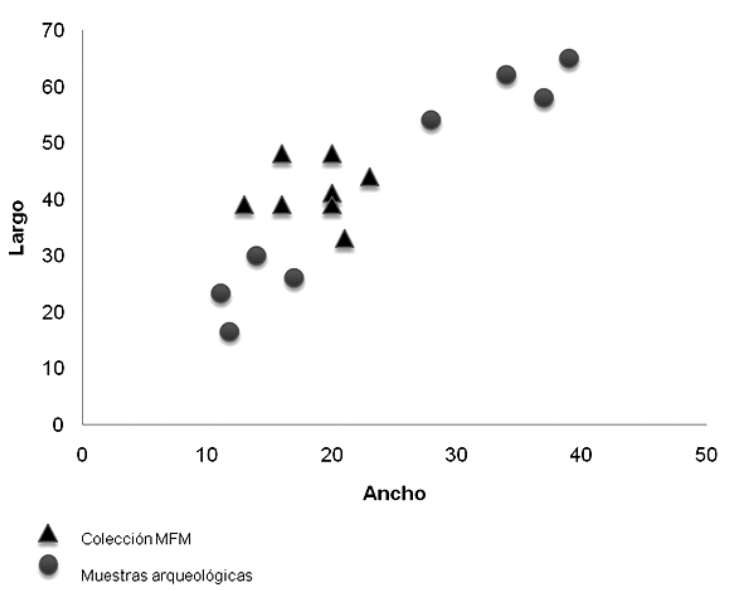

Fig. 12. Características dimensionales de las puntas arqueológicas y de la colección del Museo del Fin del Mundo.

dinámica perfecta. Si bien no fue posible medir el pedúnculo debido a que se trata de piezas enmangadas, ninguno de los astiles presenta un diámetro mayor a $10 \mathrm{~mm}$ (ver Tabla 2). Si comparamos las características dimensionales entre las piezas de museo y las arqueológicas, observamos que las primeras son más estandarizadas y presentan una superficie de refuerzo notablemente menor (Fig. 12 y 13). La prueba " $t$ " de comparación de las medias, muestra que existen diferencias significativas entre las medias de ambos conjuntos con un 95\% de confianza en lo que respecta a la superficie de refuerzo; en lo que respecta al resto de variables dimensionales las diferencias no son estadísticamente significativas.

\section{DISCUSIÓN Y CONCLUSIONES}

El entorno forestal fue utilizado por los distintos grupos del extremo sur americano como ambiente para instalación, como fuente de materia prima necesaria para la fabricación de armas de caza, la obtención de combustible y la construcción de estructuras de maderas. El estudio de colecciones de museo, sin embargo, es prácticamente el único recurso para obtener información sobre los procesos de producción y consumo de los instrumentos de madera, la inversión de trabajo, los conocimientos y habilidades técnicas vinculadas con su manufactura y uso. Su comparación con la información proporcionada por los registros arqueológicos y etnográficos permiten obtener un panorama más completo del uso del arco y la flecha por las poblaciones fueguinas,

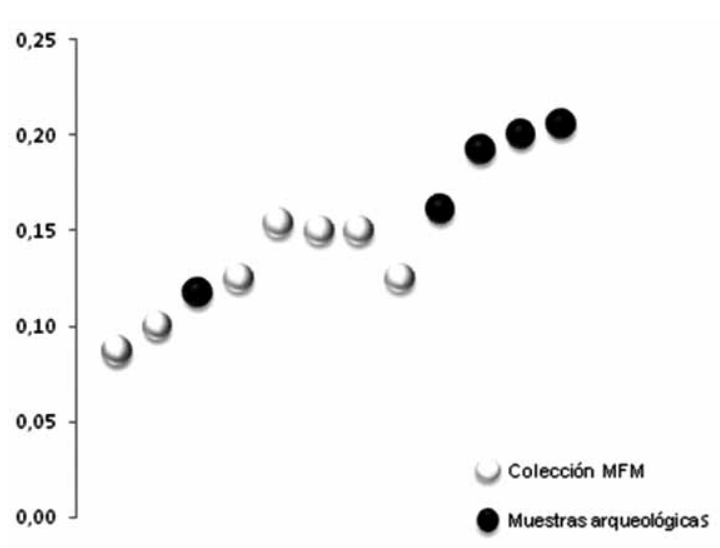

Fig. 13. Superficie de refuerzo de las puntas arqueológicas y de la colección del Museo del Fin del Mundo.

evaluar los sesgos de cada una de las muestras así como plantear nuevas preguntas de investigación sobre los cambios desarrollados por estas sociedades como consecuencia de su entrada forzosa al mundo occidental. El análisis morfológico y la identificación de las materias primas vegetales de las piezas del Museo del Fin del Mundo permitieron determinar en primer lugar, que tanto los arcos como los astiles estudiados presentan una morfología acorde con la descrita por las distintas fuentes escritas. Las características morfológicas de los distintos astiles demuestran la búsqueda de una materia prima adecuada que permitiera la fabricación de astiles rectos. Esta materia prima debía ser además flexible $y$ resistente.

En segundo lugar, este estudio permitió observar que una vez seleccionada la madera se llevaban a cabo diferentes operaciones técnicas que incluían el descortezamiento, el desbaste y la pulimentación de los arcos y astiles. De esta forma es posible inferir, sobre todo en el caso de los astiles, que la inversión de trabajo era significativa desde la búsqueda y selección de ramas rectilíneas hasta su enmangamiento con la punta. Asimismo, la mención etnográfica sobre la recuperación de los astiles, durante las actividades de caza, deja en claro el valor que poseía esta pieza, sin lugar a dudas, consecuencia del tiempo y esfuerzo empleado en su fabricación. Además de la selección y obtención de la madera, la confección de los instrumentos involucraba una serie de procesos que requerían determinados conocimientos y dominio de técnicas 
de trabajo. El análisis de los emplumados y la presencia de las sustancias adheridas apuntan también en esta misma dirección.

En lo que respecta a los recursos vegetales explotados para la manufactura de los artefactos bajo estudio se ha podido constatar que la madera utilizada -Nothofagus sp- para la construcción de los arcos coincide con las descripciones de las fuentes escritas y con los resultados expuestos en el trabajo de N. Ratto (2003). No obstante en el caso de los astiles estudiados no se registró la diversidad de especies mencionadas para su confección en las distintas fuentes consultadas. A pesar de que algunas de las especies señaladas en los registros etnográficos comparten rasgos anatómicos similares -arbustos de madera flexible y resistente- el análisis de los diez astiles a permitido comprobar que recurrentemente existe una marcada selección por la madera de Berberis sp. para la fabricación de este tipo de pieza. No obstante, cabe destacar que entre las piezas estudiadas existen astiles que han sido confeccionados con madera de una especie que coexiste con Berberis sp. Esta madera ha sido identificada como Ribes magellanicus y hasta el momento no había sido registrada en los estudios arqueobotanicos-arqueológicos como materia prima leñosa utilizada para la fabricación de astiles. Poco se sabe sobre las características físicas de la madera de Ribes magellanicus, pero resulta particularmente interesante que Chapman (1986) en sus escritos mencione el uso de este material leñoso para la confección de astiles. Deberíamos preguntarnos entonces el por qué del predominio de Berberis sp., como materia prima leñosa, sobre el resto de los arbustos existentes en la zona. Quizás la flotabilidad -característica de Ribes magellanicus apuntada por Chapman- no sea un requisito necesario o indispensable para la selección de la madera destinada a la fabricación de los astiles. Tal vez sea la resistencia de las fibras de la madera la clave para la selección de un tipo u otro de materia prima leñosa. Más allá de la materia prima utilizada en la fabricación, las características morfométricas de estos ejemples son muy similares a los astiles confeccionados sobre Berberis $s p$.

Otro aspecto interesante que resultó del análisis de esta colección es la utilización del hueso para la confección de la mayor parte de las puntas dado que los únicos registros conocidos son: la mención que se realiza en las fuentes etnográficas correspondien- tes a la sociedad Yámana y la existencia de otras colecciones etnográficas en las que se han hallado puntas de flecha óseas (Vietri 2006). No existe hasta la fecha el hallazgo de este tipo de artefactos dentro del registro arqueológico fueguino. Sin embargo, la explotación de esta materia prima está ampliamente documentada en Tierra del Fuego para la manufactura de diversos instrumentos de captura y procesamiento de recursos, fundamentalmente en las sociedades especializadas en la gestión de recursos marinos (Scheinsohn 1997; Orquera y Piana 1999). Es decir que los conocimientos y técnicas para la transformación de este tipo de materiales no resultan extraños a estas sociedades. Aún no está claro si se trata de una modificación tardía, del mismo modo que ocurre con el uso del vidrio. No obstante, el análisis morfométrico demuestra una similitud en el diseño con las puntas arqueológicas. Estos resultados respaldan además el modelo de asignación funcional propuesto por Ratto (2003) en lo que respecta a las variables de perfomance necesarias en el sistema del arco y la flecha.

Por último, la comparación con los conjuntos analizados por otros investigadores ha demostrado una cierta estandarización entre las colecciones. Sólo el diámetro de los astiles muestra diferencias significativas entre el conjunto del Museo del Fin del Mundo con respecto a las restantes colecciones. Una posibilidad sería que esta diferencia se deba a la necesidad de compensar el menor peso de las puntas óseas; sin embargo la muestra es aún es muy pequeña como para realizar afirmaciones contundentes.

En síntesis, los análisis presentados en estas páginas no sólo brindan información sobre el uso de los recursos vegetales por parte de las sociedades fueguinas sino que también abren toda una serie de interrogantes en lo que respecta a la adopción del arco y la flecha y las modificaciones tecnológicas y organizativas que ello comporta.

\section{AGRADECIMIENTOS}

Queremos agradecer a Carole Cheval por el diseño de los dibujos, a Claire Delhon por la lectura y comentarios sobre el estudio arqueobotanico del material y al Laboratoire d'Archéobotanique de CEPAM (Centre d'études Préhistoire Antiquité Moyen Age), laboratoire du CNRS por la utilización 
del equipamiento necesario para el desarrollo de nuestro trabajo. Nélida Pal prestó ayuda en el análisis morfo-técnico de las puntas.

\section{BIBLIOGRAFÍA}

ALVAREZ M. R. 2003. Organización tecnológica en el canal Beagle: el caso de Túnel I (Tierra del Fuego). Tesis doctoral, Universidad de Buenos Aires. Ms.

ALVAREZ M. R. e.p. Puntas de arma del extremo sur de Patagonia: algunas consideraciones sobre diseño y contexto de uso. En Armas prehispánicas: múltiples enfoques para su estudio en Sudamérica. Editado por D. Bozzuto y J. Martínez. Editorial Fundación Azara

ALVAREZ M. R. 2010. Tendencias y cambios en las prácticas tecnológicas de los grupos cazadores-recolectores del extremo sur Sudamericano. En Arqueología de Patagonia: Una mirada desde el último confín, 19-33. Editado por M. Salemme, F. Santiago, M. Álvarez, E. Piana, M. Vázquez y M. Mansur. Editorial Utopías.

ANCÍBOR, E y C. PÉREZ DE MICOU 2002. Reconocimiento de especies vegetales combustibles en el registro arqueológico de la estepa patagónica. En Plantas y Cazadores en Patagonia, compilado por C. Pérez de Micou, pp. 15: 32. Editado por Facultad de Filosofía y Letras Universidad de Buenos Aires, Argentina.

BARTHELEMY, D., C. BRION y J. PUNTIERI 2008 Pantas Patagonia. Editorial Vazquez Mancini. Buenos Aires. Argentina.

BEAUVOIR, J. M. (1915, ed. Facsímile): Diccionario Shelknam. Indígenas de Tierra del Fuego. Sus tradiciones, costumbres y lengua. Zagier and Urruty Publications. Ushuaia.

BRIDGES, L. 1952. El último confín de la tierra. Ediciones Marymar. Buenos Aires.

BOGDANOVIC I., E. CAMAROS, H. DE ANGELIS, A. LASA, M.A. MANSUR, A. MAXIMIANO, V. PARMIGIANI, R. PIQUE y O. VICENTE 2009. El paraje Ewan, un lugar de reunión Selk'nam en el centro de la isla (Tierra del Fuego, Argentina). En Arqueología de Patagonia: Una mirada desde el último confín, 941-956. Editado por M. Salemme, F. Santiago, M. Álvarez, E. Piana, M. Vázquez y M. Mansur. Editorial Utopías, Ushuaia.

BUXÓ, R., R. PIQUÉ 2003. La recogida de muestras en arqueobotánica: objetivos y propuestas metodológicas. Museu d'Arqueologia de Catalunya. Barcelona.

CARUSO, L. 2008. Los usos de la madera entre los cazadores recolectores Selknam de Tierra del Fuego (Argentina). Treball de recerca-Doctorat d'Arquelogía Prehistòrica, Universidad Autónoma de Barcelona.
CLEMENTE, I. 1997. Los instrumentos líticos de Túnel VII: una aproximación etnoarqueológica. Treballs d'etnoarqueologia, 2. Universidad Autónoma de Barcelona. Barcelona.

COJAZZI, A. 1914. Los indios del Archipielago Fueguino. Revista Chilena de Historia y Geografía 9: 288-352; 10: 5-51.

CORREA, M.N. (Dir.) 1998. Flora patagónica. Parte I. Colección Científica del INTA. Buenos Aires.

CHABAL L. 1982. Méthodes de prélèvement des bois carbonisés protohistoriques pour l'étude des relations hommes-végétation. D.E.A, Uni. Montpellier II, 54p.

CHAPMAN, A. 1986. Los Selk'nam. La vida de los Onas. Emecé editores. Buenos Aires.

DE ANGELIS H. 2009. El vidrio como materia prima introducida en el periodo de contacto europeo en Tierra del Fuego. En Arqueología de Patagonia: Una mirada desde el último confín, 335-348. Editado por M. Salemme, F. Santiago, M. Álvarez, E. Piana, M. Vázquez y M. Mansur. Editorial Utopías. Ushuaia.

ESTÉVEZ, J. y A. VILA 2006. Colecciones de museos etnográficos en arqueología. Etnoarqueología de la Prehistoria más allá de la analogía, Treballs D'Etnoarquología 6:241-254.

GALLARDO, C. 1910. Los Onas. Buenos Aires: Cabaut \& Cia. $1^{\circ}$ reimpresión, Ushuaia: Zagier \& Urruty.

GARRIDO, C. y D. FERNANDEZ 2007. Flora Patagônica. Editorial Fantástico Ser. Punta Arenas Chile.

GUSINDE, M. 1937. Los indios de Tierra del Fuego. Tomo 1: Los Selk'nam. 2 vols. Centro Argentino de Etnología Americana, Buenos Aires.

HASTORF, C.A. 1999. Recent Research in Paleoethnobotany. Journal of Archaeological Research 7 (1): 55-103.

HUGHES, S. 1998. Getting to the Point: Evolutionary Change in Prehistoric Weaponry. Journal of Archaeological Method and Theory 5 (4): 345-408.

HYADES P. D. y J. DENIKER 1891 Anthropologie et Ethnographie. Mission Scientifique du Cap Horn (1882-1883), vol. VII. Paris.

INSIDE WOOD:http://insidewood.lib.ncsu.edu/search.2

KNETCH, H. (ed). 1997. Projectile technology. Plenum Press. New York.

LOTHROP S.K. 1928. The Indians of Tierra del Fuego. Contributions from the Museum of the American Indian (Heye Foundation).

MARCONETTO, M.B. 2002. Análisis de los vestigios de combustión de los Sitios Alero Don Santiago y Campo Moncada En Plantas y Cazadores en Patagonia, compilado por C. Pérez de Micou, 33-54. Editado por Facultad de Filosofía y Letras, Universidad de Buenos Aires, Argentina. 
MOORE, D.M. 1983. Flora of Tierra del Fuego. Antony Nelson, Englan, and Missouri Botanical Garden, U.S.A.

ORQUERA L.A. y E.L. PIANA 1986. Normas para la descripción de la piedra tallada. Contribución Científica $N^{\circ} 1$, Publicación Especial, Centro Austral de Investigaciones Científicas (CONICET), Ushuaia.

ORQUERA L.A. y E.L. PIANA 1999a. Arqueología de la región del canal Beagle (Tierra del Fuego, Republica Argentina). Publicaciones de la Sociedad Argentina de Antropología.

ORQUERA L. A. y E.L. PIANA 1999b. La vida material y social de los Yámana. Eudeba. Buenos Aires.

PIANA E., VAZQUEZ M., ALVAREZ M, y RUA N. 2007. El sitio Ajej I: Excavación de rescate en la costa del canal Beagle. Arqueología Argentina en los Inicios de un Nuevo Siglo. Publicación del XIV Congreso de Arqueología Argentina. Tomo I. F. Oliva, N. de Grandis y J. Rodríguez Comp.

PIANA E., VAZQUEZ M. y ALVAREZ M. e.p. Nuevos resultados del estudio del sitio Ajej I: un aporte a la variabilidad de estrategias de los canoeros fueguinos. Runa.

PIQUÉ, R. 2006. "L'uso del legno nelle società fuegine: manufatti dalle collezioni del Museo Pigorini". En Finis Térrea.Viaggiatori, esploratori e missionari italiani nella Terra del Fuoco. 182-192.Editado por Salerno, A.; Taglaiacozzo, A. Museo Nazionale Prehistórico Etnografico "Luigi Pigorini". Ministero per i Beni e le attivitá culturali. Roma.

PIQUÉ I HUERTA, R. 1999. Producción y uso del combustible vegetal: una evaluación arqueológica. Universidad Autónoma de Barcelona, Consejo Superior de Investigaciones Científicas, Madrid.

PRIETO IGLESIAS, A. 1994. Arquería Selk'nam: La guerra y la paz en la Tierra del Fuego. Ed.: Colegio Punta Arenas, Punta Arenas. Chile.

PUJANA R., BURRIEZA H y CASTRO M. A. 2008. Wood anatomy of Ribes magellanicum (Grossulariaceae). Boletin Sociedad Argentina de Botánica n 43 (1-2): 61 - 65.

RAPOPORT, E. H., LADIO, A., y SANZ, E. H. 2003. Plantas nativas comestibles de la Patagonia andina argentino/ chilena. Parte I. Departamento de ecología. Centro regional universitario de Bariloche. San Carlos de Bariloche.

RATTO, N. 2003. Estrategias de caza y propiedades del registro en la Puna de Chaschuil (Depto Tinogasta, Catamarca, Argentina). Tesis Doctoral, Universidad de Filosofía y Letras, Buenos Aires.

RIVERA, E. M. 1973-2002. Aporte de la Xilología al estudio dendrocronológico de Nothofagus en la Argentina. Ianigla, Pp: 25-29.

SCHEINSOHN, V. 1997. La explotación de materias primas óseas en la Isla Grande de Tierra del Fuego. Tesis Doctoral. Universidad de Buenos Aires.

SARMIENTO DE GAMBOA, P. 1988 Los viajes al estrecho de Magallanes. Alianza editorial. Madrid.

SOLARI, M. E. 1992. Anthracologie et ethnoarchéologie dans l'archipel du cap Horn (Chili). Boletín de la Société Botanique de France 139: 407-420. París.

SOLARI, M. E. 1993. Lhomme et le bois en patagonie et terre de feu au cours des six derniers millénaires: Recherches anthracologiques au Chili et en Argentine. Thèse Université Montpellier II, Montpellier. France.

SOLARI, M. E. 1994. Estudio antracologico del archipielago del Cabo de Hornos y Seno Grandi. Anales del Instituto de la Patagonia 22: 137-148.

SUBY, J. SANTIAGO, F. y SALEMME, M. 2008. Análisis paleopatológico de los restos humanos del sitio Puesto Pescador 1 (Tierra del Fuego). Magallania, 36 (1) :3-64.

THE INTERNATIONEM PLANT NAMES INDEX: http://www. ipni.org/ipni/idPlantNameSearch.

VERNET J. 1973. Etude sur l'histoire de la végétation du sudest de la France au quaternaire d'aprés les charbons de bois principalment. Paléobiologie continentale IV $n^{\circ} 1$.

VIETRI, L. 2006. Storia e microstorie. Le collezioni della Terra del Fuoco del Museo "Luigi Pigorini. En Finis Terrae. Viaggiatori, exploratori e missionari italiani nella Tierra del Fuoco, 259-285. Editado por Salerno, A.; Taglaiacozzo, A. Museo Nazionale Prehistórico Etnografico "Luigi Pigorini". Ministero per i Beni e le attivitá culturali. Roma. 